\title{
„SOZIALFASCHISMUS” IN DEUTSCHLAND
}

\section{ZUR GESCHICHTE EINES POLITISCHEN BEGRIFFS}

Seit seiner Entstehung hatte sich der vor allem aus dem linken Flügel der Vorkriegssozialdemokratie hervorgegangene deutsche Kommunismus scharf von der SPD distanziert, deren „Ersatz-Marxismus”, wie Rosa Luxemburg auf dem Gründungsparteitag der KPD am 3 I. Dezember ${ }_{191} 8$ meinte, die sozialistische Bewegung ,zu einem Dahinsiechen im Rahmen und auf dem Boden der kapitalistischen Gesellschaft verurteilte, ohne jedes ernste Bestreben, die Gesellschaft zu erschüttern und aus den Fugen zu bringen". Trotz all ihrer Differenzen in wichtigen Fragen waren sich Lenin und Luxemburg einig in ihrem $\mathrm{Ha}$ gegen die „Sozialverräter”, wie Lenin die Sozialdemokraten verächtlich nannte. Und Rosa Luxemburg sagte von ihnen und den deutschen Gewerkschaftsführern, sie seien die ,infamsten und größten Halunken, die in der Welt gelebt haben”; ihre „sogenannte sozialistische Regierung” sei in Wirklichkeit eine „Regierung der bürgerlichen Konterrevolution". ${ }^{1}$ Die Frontstellung gegen die Sozialdemokratie bestimmte also bereits die Politik der jungen KPD und der im März I9I9 gegründeten Kommunistischen Internationale, ehe am 23. März I919 auf der Piazza San Sepolcro in Mailand von dem ehemaligen Sozialisten Mussolini die „Fasci di Combattimento” ins Leben gerufen wurden und Hitler im September desselben Jahres in die winzige „Deutsche Arbeiterpartei” eintrat, die einige Monate später den Namen „NSDAP” erhielt. Der Kampf gegen diese beiden politischen Gruppierungen, die Sozialdemokratie und den „Faschismus”, bestimmte in der Periode der Weimarer Republik in nicht geringem Maße die Politik der KPD. Wir wollen die Entwicklung des kommunistischen Verhältnisses zur Sozialdemokratie sowie vor allem die Geschichte des Begriffs „Sozialfaschismus” in Deutschland in einem kurzen Überblick betrachten.

1 R. Luxemburg in: Bericht über den Gründungsparteitag der KPD (Spartakusbund) vom 30.1 2.1918 bis 1.1.1919, [Berlin 1919,] S. 24, 37, 29. - „Mit dem Gefühl tiefster Bitterkeit" hatte Lenin im September 1914 geschrieben, „daß die Haltung der Führer ... insbesondere der deutschen Partei, an direkten Verrat an der Sache des Proletariats grenzt" (W.I.Lenin, Werke, Bd. 21, Berlin 1960, S. 15). 
Die Haltung der Kommunisten gegenüber den Mehrheitssozialdemokraten hatte sich durch die Ermordung von Rosa Luxemburg und Karl Liebknecht im Januar I9I9 weiterhin verschlechtert. Symptomatisch dafür war die erste Reaktion der KPD-Führung beim Kapp-Lüttwitz-Putsch am I 3. März 1920. In dem Aufruf der Zentrale vom gleichen Tage hieß es: „Das revolutionäre Proletariat ... wird keinen Finger rühren für die in Schmach und Schande untergegangene Regierung der Mörder Liebknechts und Luxemburgs. ... Die demokratische Republik ist rettungslos verloren, nicht sie gilt es zu retten, der die Arbeiter einen Fluch ins Grab nachschleudern und die sie im Innersten ihres Wesens als eine Lüge und einen Betrug erkannt haben." Abgelehnt wurde der Aufruf der „,blutbedeckten Verräter des Sozialismus" zur Sammlung und zum Generalstreik gegen die Putschisten. Stattdessen wurde für die eigene Aktion auf den Augenblick vertröstet, in dem sich das Gesicht der Militärdiktatur enthüllt haben werde, das so aussehe: „Progrome, blutige, eiserne Unterdrückung der gesamten Arbeiterklasse, die reine, nackte Gewalt im Innern; es bedeutet nach außen Kriegsgefahr."1 Trotz dieser Voraussicht weigerte sich die KPD-Führung zunächst, sich dem Widerstand gegen Kapp und Lüttwitz anzuschließen; erst am I s. März stimmte sie dem Streikaufruf der Gewerkschaften und der beiden sozialdemokratischen Parteien zu. Hier zeigte sich schon zu Beginn der Weimarer Republik die Zwiespältigkeit der kommunistischen Position: Die KPD war sich mit den ihr politisch ferner stehenden Rechtsradikalen einig in der Ablehnung des von der Sozialdemokratie grundsätzlich bejahten demokratischen Staats, was in der Konsequenz zu einer Stärkung der Position der „Rechten” führen konnte.

Die KPD der Weimarer Republik war eine Sektion der Kommunistischen Internationale. In den Jahren 1921-1924 wurden in dieser die Prinzipien der „Einheitsfronttaktik” entwickelt, gleichzeitig traten der italienische und der internationale, besonders der deutsche „Faschismus" in ihr Blickfeld, ferner begann der Prozeß der sogenannten „Bolschewisierung” der kommunistischen Parteien. Eine nähere Betrachtung wird zeigen, daß bereits in jenen Jahren die Grundlagen gelegt wurden für die spätere, so folgenreiche Beurteilung der Sozialdemokratie und des „Faschismus” in Deutschland. Zunächst einmal aber müssen wir die auswechselbaren Spielarten der kommunistischen „Einheitsfronttaktik” betrachten.

1 Die Rote Fahne III, Nr. 30 (1 4.3.I920). - Oft wurde damals der Kapp-Putsch mit dem russischen Kornilow-Putsch im September 1917 verglichen (z.B.: Lenin, Sämtliche Werke, Bd. XXV, Wien-Berlin I930, S. III, $297 \mathrm{ff}$; Braun[-Bronski] in: Dic Internationale II, 1920, Nr. 23, S. 32 ff.; dagegen E. Hoernle, ebd., Nr. 25, S. 40). 
Während noch auf dem II. Kongreß der Komintern im Juli/August 1920 Sinowjew der Meinung gewesen war, daß die Dritte die Zweite Internationale besiegt habe, und Lenin den sozialdemokratischen „Opportunismus” zum Hauptfeind erklärt hatte, ${ }^{1}$ wurde auf dem III. Kongre $ß$ die Parole „Zu den Massen!" ausgegeben, die dazu dienen sollte, die „Mehrheit der Werktätigen” zu erobern. „Die Kommunisten sind an der Zusammenfassung aller Kräfte der Arbeiterklasse gegen den Kapitalismus interessiert", hieß es in den vom IV. Kongreß beschlossenen Thesen über die Taktik der Komintern. Verhandlungen über gemeinsame Aktionen mit den ,verräterischen Führern” der Sozialdemokratie und der reformistischen Gewerkschaften über die gemeinsame Führung der „täglichen Kämpfe der breiten Arbeitermassen um ihre notwendigsten Lebensinteressen" wurden erlaubt, falls nur die Freibeit für selbständige Aktionen der kommunistischen Parteien gewahrt bleibe. ${ }^{2}$ Auf dem im Juni/Juli I924 abgehaltenen V. Kongreß legte man die verschiedenen Arten der Einheitsfronttaktik als einer „Methode der Agitation und der revolutionären Mobilisation der Massen für die Dauer einer Periode" fest. Drei Arten der Einheitsfronttaktik wurden unterschieden: I. Die Einheitsfronttaktik von unten, also mit den Arbeitern unter Umgehung einer Verständigung mit den Funktionären der sozialdemokratischen Parteien und der Gewerkschaften. 2. Die Einheitsfronttaktik von unten und von oben, die zuweilen in den Ländern angewandt werden müsse, in denen die Sozialdemokratie noch eine bedeutende Macht darstelle. Die 3. Einheitsfronttaktik, nur von oben, wurde als mögliche Methode „kategorisch und entschieden" verworfen. Man kann sagen, daß fortan die Anwendung der „Einheitsfronttaktik nur von unten” ein wichtiges Kennzeichen der Linkspolitik, der Gebrauch der Einheitsfronttaktik von unten gepaart mit Spitzenverhandlungen ein Hauptmerkmal der Rechtstaktik der kommunistischen Parteien war. Gleichgültig aber, welche Taktik angewandt wurde, ihr Ziel war das ,allmähliche Herüberziehen der sozialdemokratischen und des besten Teiles der parteilosen Arbeiter" zu den Kommunisten. Jede Einheitsfrontpolitik war „die Taktik eines revolutionären strategischen Manövers der ...

- Der II. Kongreß der Kommunistischen Internationale. Protokoll der Verhandlungen vom 19.7. in Petrograd und vom 23.7. bis zum 7.8. in Moskau, [Hamburgl 1921, S. 8, vgl. I I 2 (Sinowjew), 738 (Manifest), 36 (Lenin): „Der Opportunismus ist unser Hauptfeind. Der Opportunismus in den Oberschichten der Arbeiterklasse ist kein proletarischer, sondern bürgerlicher Sozialismus. Der praktische Beweis dafür ist, daß die Führer, die innerhalb der Arbeiterbewegung der opportunistischen Bewegung angehören, bessere Verteidiger der Bourgeoisie sind als die Bourgeois selbst. Ohne ihre Unterstützung könnte sich die Bourgeoisie den Arbeitern gegenüber nicht behaupten."

2 Protokoll des IV. Kongresses der Kommunistischen Internationale. Petrograd-Moskau vom 5.II. bis 5.I2.1922, [Hamburg] 1923, S. Io14f. 
kommunistischen Vorhut in ihrem Kampfe vor allem gegen die verräterischen Führer der konterrevolutionären Sozialdemokratie". ${ }^{1}$

Die KPD verfolgte in den Jahren $192 \mathrm{I}-1923$ eine Politik der Einheitsfront gegenüber der Sozialdemokratie, die einerseits über verschiedene „Etappenforderungen" zur - allerdings in den kommunistischen Reihen selbst umkämpften - Forderung der "Arbeiterregierung” führten, während andererseits gleichzeitig die ,verantwortlichen Führer, die vom deutschen Proletariat zur Wahrung der Klasseninteressen betraut sind", als "gelbe Generäle”, die „im Lager des Feindes" ständen, scharf kritisiert wurden. ${ }^{2}$ Trotz aller Angriffe auf die "Scheinsozialisten" wurde z. B. in einem im November 192 I publizierten Resolutionsentwurf rein sozialistischen Regierungen die parlamentarische Unterstützung zugesichert, so lange diese im Interesse der Arbeiterschaft liegende Maßnahmen träfen. Gleichzeitig jedoch sollten solche Regierungen in der Propaganda als „Vorposten der Bourgeoisie” und „letzte Etappe der bürgerlichen Demokratie” angegriffen werden. ${ }^{3}$

In diesem Stadium fehlte noch jeder Hinweis auf die Existenz eines „Faschismus" in Deutschland, geschweige denn ein solcher auf eine angebliche Verwandtschaft zwischen ihm und der Sozialdemokratie. In seinem Referat auf dem KPD-Parteitag im August 192I erwähnte Ernst Meyer lediglich den mit der „Orgesch” gleichgesetzten „Stahlhelm” als „illegales Unterdrückungsmittel der Arbeiterschaft durch die Bourgeoisie", und Arthur Rosenberg bezeichnete zur gleichen

1 Thesen und Resolutionen des V. Weltkongresses, Hamburg 1924, S. 25-27. Vgl. Language of Politics. Hrsg. Lasswell-Leites, New York 1949, S. 298 f.; J. Degras, „United Front tactics in the Comintern I921-I928", in: St Antony's Papers no. 9, London 1960, S. 9-22; Bericht über die Tätigkeit des Präsidiums und der Exekutive der Kommunistischen Internationale für die Zeit vom 6.3. bis 11.6 .1922 , [Hamburg] 1922, S. 123 : „... ist es nötig, daß wir in dem Kampf gegen die Faszisten die Initiative ergreifen und ... lokale gemeinsame Komitees zur Bekämpfung der Faszisten zusammen mit den anderen Arbeiterparteien und -organisationen vorschlagen. Es handelt sich dabei gar nicht um Konzessionen an die Sozialisten. Im Gegenteil: die Taktik der Einheitsfront schließt nicht die Verschärfung unseres Kampfes aus. Man kann behaupten, je erfolgreicher sie angewandt wird, desto schärfer auch unser Kampf den Sozialisten gegenüber." (Sinowjew).

${ }^{2}$ Vgl. Die Internationale IV (I922), S. s68f. (A. Thalheimer), I95 (H. Remmele), $592 \mathrm{ff}$. (A. Kleine[-Guralski]): „Die Führer der SPD sind keine Reformisten mehr, sie sind Liquidatoren aller Reformen und Errungenschaften des Proletariats nicht nur während der letzten Jahre, sondern während der letzten drei und vier Generationen...”. - Es sei an Sinowjews Bemerkung vom Januar I 924 erinnert: „... Es wäre ja nicht so schwer, so eine gummiartige Formel zu finden, da sind wir ja alle Meister drin; einerseits, nicht nur, sondern." (Die Lehren der deutschen Ereignisse. Das Ptäsidium des EKKI zur deutschen Frage, Hamburg 1924, S. 66).

${ }^{3}$ Die Internationale III (I92 I), S. 337 (A. Friedrich), 52 I (Resolutionsentwurf). 
Zeit die „weißgardistischen Banden” der „sogenannten Faszisten” als „italienische Orgesch". ${ }^{1}$ In den vom III. Weltkongreß am r 2. Juli I92 I angenommenen Thesen über die Taktik wurde übrigens die KPI aufgefordert, „unbeugsam gegen die opportunistische Politik des Serratismus” zu kämpfen und sich mit „den Massen des Proletariats” im Kampf gegen die Konterrevolution zu verbinden. ${ }^{2}$

Auf dem im November und Dezember 1922 stattfindenden IV. Kominternkongre $\beta$ beschäftigten sich die Kommunisten zum ersten Mal eingehender mit dem italienischen und dem internationalen Faschismus. Als charakteristisches Merkmal des „klassischen” italienischen Faschismus betrachtete man dort die gleichzeitige Anwendung von konterrevolutionärer Kampforganisation und sozialer Demagogie; hier begegnen wir aber auch schon der Ansicht, der Faschismus sei „die letzte Karte im Spiele der Bourgeoisie”, denn seine Herrschaft richte sich auch ,gegen die Grundlagen der bürgerlichen Demokratie überhaupt". ${ }^{3}$ In seiner Analyse des Charakters und der Doktrin des italienischen Faschismus hob Amadeo Bordiga, damals der wichtigste Führer der italienischen Kommunistischen Partei, hervor, daß es sich hier um eine reaktionäre Kampforganisation handele, die mit einer Mischung von brutaler Gewalt, zynischer Demagogie, „exaltiertem Patriotismus" und Antisozialismus in den dem Proletariat am nächsten stehenden Schichten der Mittelklasse, der Kleinbürger, Teilen der „intellektuellen Elemente der bürgerlichen Jugend” und sogar unter

1 Bericht über die Verhandlungen des 2. Parteitages der KPD, abgehalten in Jena vom 22. bis 26.8.1921, Berlin 1922, S. 224; Die Internationale III, S. 432, 428 (Rosenberg). - Die „Orgesch” (Organisation Escherich) war 1920/21 eine rechtsgerichtete bayerische "Selbstschutzorganisation”; ihr Gründer war der Forstrat G. Escherich. Der „Stahlhelm, Bund der Frontsoldaten" war eine Ende 1918 von F. Seldte gegründete Organisation von Kriegsteilnehmern, die sich 1929 der „Nationalen Einheitsfront” (DNVP, NSDAP) anschloss, 1933/34 ,gleichgeschaltet" und 1935 aufgelöst wurde.

2 Thesen und Resolutionen des III. Weltkongresses der Kommunistischen Internationale, [Hamburg] i 921, S. 39 f., vgl. 56 f. über „das Verhältnis zu den proletarischen Mittelschichten”, die z.T. ins "Lager der offenen Kontertevolution, teils in das Lager der Revolution" gingen, sowie Lenin, Werke, Bd. 32, Berlin I96I, S. 546 . - G.M. Serrati war der Führer der „terzinternationalistischen” „Maximalisten” in der PSI, die sich I924 der PCI anschlossen.

a Protokoll IV. KI-Kongress, S. IoI If. (Resolution „Über die Taktik der KI”). Vgl. Sinowjew am 25.6.1921: „Die Fascisten sind ganz gute Chirurgen; sie machen ihre Schlächterarbeit an der italienischen Atbeiterklasse sehr gewissenhaft und gründlich. Die Schuld der [sozialistischen] Partei und speziell Serratis besteht darin, daß sie den günstigen Augenblick des Kampfes verpaßt und objektiv der Bourgeoisie die Arbeiterklasse ausgeliefert haben." (Protokoll des III. Kongresses der KI, Moskau, 22.6.-1 2.7.1921, [Hamburg] 1921, S. 166f.); ferner „Thesen der KPI. Zur Frage der Taktik”, in: Inprekorr II (1922), S. 565-572. - Tasca und Gramsci hatten kurz zuvor den Faschismus als ,seinem Wesen nach eine agrariscbe Bewegung" beurteilt (Die RGI II, 1922, S. 734). Vgl. Inprekorr II (I922), S. I 255 f. (U. Terracini). 
den landwirtschaftlichen Arbeitern und "gewissen weniger qualifizierten Kategorien der städtischen Arbeiterschaft" Anhänger zu gewinnen vermocht habe. Außerdem könne sie sich der Unterstützung des Staates und der Großbourgeoisie erfreuen. ${ }^{1}$

Wenn auch das Regime des italienischen Faschismus Ende 1922 kaum mit dem des deutschen Nationalsozialismus nach 1933 zu vergleichen ist, so fällt doch die relativ illusionistische Einschätzung des Faschismus zu jener Zeit auf. Weder Kommunisten noch Sozialisten vermochten den Charakter der militanten antisozialistischen Bewegungen voll zu begreifen. So sagte etwa Bordiga kurz nach dem Marsch auf Rom voraus, „daß der Faschismus liberal und demokratisch sein wird". ${ }^{2}$ Zusammenfassend sagte Bordiga auf dem IV. Weltkongreß: „Unserer Meinung nach ist der Faschismus ein Mittel, sich durch alle den herrschenden Klassen zur Verfügung stehenden Mittel die Macht $\mathrm{zu}$ sichern... Sobald es sich um eine ökonomische Krise handelt, genügt der Staat nicht, um die Macht aufrechtzuerhalten. Es bedarf einer einheitlichen Partei, einer einheitlichen gegenrevolutionären Organisation. Die Fascistenpartei ist infolge ihrer Berührung mit der gesamten Bourgeoisie in gewisser Hinsicht dasselbe, was in Rußland die KP infolge ihrer Beziehungen zum Proletariat ist, nämlich ein leitendes und kontrollierendes Organ des gesamten Staatsapparates, das gut organisiert und diszipliniert ist. ... Sie ist das leitende bürgerliche Organ des Staates in der Periode des Niederganges des Imperialismus."3 Dies war die erste ausführliche Beurteilung des neuen politischen Phänomens „Faschismus” vor dem höchsten Gremium der Kommunistischen Internationale. Ergänzt wurde sie durch die Behauptung in der Resolution zur italienischen Frage, daß „die wirklichen Vorläufer und Wegbereiter des Faschismus” unstreitig die „Reformisten”, d.h.

1 Protokoll IV. KI-Kongreß, S. 330-350. Vgl. u.a.: F. Borkenau, „Zur Soziologie des Faschismus", in: Archiv für Sozialwissenschaft Bd. 68 (1933), S. 513-547; S. M.Lipset, „Der ,Faschismus' - die Linke, die Rechte und die Mitte”, in: Kölner Zs. f. Soziologie u. Sozialpsychologic XI (1959), S. 40I-444. - Bordiga (geb. I889), Ingenieur, Führer der PSI-Sektion Neapel, I $921 / 22$ der wichtigste Führer der PCI I 930 als "Ultralinker” aus der Partei ausgeschlossen. Vgl. G. Galli, storia del p.c.i., Mailand 1958.

2 Auch Lenin hat damals offenbar die Bedeutung der faschistischen Bewegung nicht richtig begriffen, sonst hätte er kaum sagen können: „Vielleicht werden uns z.B. die Faschisten in Italien gute Dienste leisten, indem sie den Italienern klarmachen, daß sie noch nicht genügend aufgeklärt sind und daß ihr Land noch nicht gegen Schwarzhunderterbanden gefeit ist." (Lenin, Werke, Bd. 33, Berlin 1962, S. 417) - Lenin hat, worauf auch H. Brahm (,Die bolschewistische Deutung des deutschen ,Faschismus' in den Jahren 1923 bis 1928 ", in: Jb. f. Gesch. Osteur. NF XII, 1964, S. 390-365) hinweist, keine fertige Formel für die Beurteilung des faschistischen Phänomens hinterlassen.

3 Protokoll IV. KI-Kongreß, S. 347; vgl. das Protokoll des V. KI-Kongresses (bes. Sinowjews und Bordigas Reden) sowie P. Togliatti, La formazione del gruppo dirigente del p.c.i. nel 1923-1924, Rom 1962, S. I8f., $30 \mathrm{ff}$. 
die Rechtssozialisten, seien. „Der Reformismus ist der Feind”, hieß es bereits Ende 1922. Allerdings wurde gleichzeitig der Zusammenschluß der Kommunisten mit den „zentristischen” Linkssozialisten (Maximalisten), der dann auch wirklich im Juni 1924 stattfand, vorgeschlagen. Sinowjew erklärte bei der Begründung dieses einstimmigen Beschlusses der italienischen Kommission des EKKI, gegen den sich ein Teil der KPI-Delegierten gesträubt hatte, aber ebenfalls : „Der Reformismus ist unser Hauptfeind."1

Ebenfalls im Jahre 1922 begann die erste kommunistische Beschäftigung mit dem Nationalsozialismus, den man als eine deutsche Spielart des Faschismus betrachtete. Edwin Hörnle, damals Mitglied der KPD-Zentrale, warnte auf dem IV. Kongreß der Komintern, daß der Nationalsozialismus gefährlich werden könne. Er unterschied zwei Typen der deutschen faschistischen Bewegung, einen süd- und einen norddeutschen. Während der süddeutsche, besonders in Bayern verbreitete Faschismus (Hitler) eine Verbindung der ,,äußersten monarchistischen Gegenrevolution” mit „breiten, an sich demokratischen Schichten" des Kleinbürger- und mittleren Bauerntums sei, stütze sich die norddeutsche Form (z.B. die „Deutschvölkischen” unter Führung A. von Gräfes) auf Teile der Landarbeiter, die sich vom Landbund gegründeten „gelben” Gewerkschaften angeschlossen hätten, und auf illegale Frontkämpferorganisationen. Mit einer gewissen Besorgnis wurde Anfang 1923 festgestellt, daß man in Deutschland aus dem faschistischen Sieg in Italien nicht viel gelernt habe. Auf dem 8. KPD-Parteitag Anfang 1923 sprach Ernst Meyer sogar bereits von der ursprünglich gehegten Befürchtung, daß die von „einem österreichischen Führer Hitler" geleiteten „bayrischen Faschistenbanden” am 9. November 1922 einen Aufstand hätten veranstalten wollen. Als besonders gefährlich beim deutschen Faschismus wurde übrigens dessen "Arbeiterfreundlichkeit" betrachtet. ${ }^{2}$ Die kommunistischen Vorwürfe gegenüber den „deutschen Faschisten" schwankten damals zwischen den Anschuldigungen des Nationalismus und des Landesverrats. $^{3}$

Im Laufe des Frühjahrs und Sommers 1923 nahm die Intensität der

1 Protokoll IV. KI-Kongreß, S. 999 f., 914f., vgl. 979 (Sinowjew); vgl. Togliatti, a.a.O., S. $30 \mathrm{f}, 46 \mathrm{ff}$., I 49 f., 2 I I ff., $223 \mathrm{ff}$; Galli, a.a.O., S. $76 \mathrm{ff}$.

2 Ebd., S. 386 (Hörnle). Vgl. Die Internationale V (1922), S. 301-304 (A. Jacobsen), 26r-267 (P. Böttcher); ebd. VI (1923), S. I I6ff. (Leonid - A. Friedrich); Inprekorr II, S. I 832 f. (H. Tittel); Bericht über den III. (8.) KPD-Parteitag, Leipzig 28.1.-1.2.1923, Berlin [1923], S. 34 f. (Meyer), 317 f. (H. Brandler).

3 Vgl. H. Neumann, "Poincarés deutsche Faschisten”, in: Inprekorr III (I923), S. 949 f. Zur damaligen Einschätzung des „Faschismus” durch die Linke vgl.: Bericht über die Verhandlungen des IX. Parteitages der KPD, abgehalten in Frankfurt/M. vom 7. bis 10.4.1924, Berlin 1924 , S. $146 \mathrm{f}$. 
Warnungen vor der akuten faschistischen Gefahr in Deutschland ständig zu. Im März fand in Frankfurt/M. die erste internationale antifaschistische Konferenz, am 29. Juli der erste Antifaschistentag im Reich statt. Nunmehr wurde davor gewarnt, „alles unter einen Hut [zu] bringen und jede Äußerung der Reaktion Faschismus [zu] nennen" (Sinowjew auf der EKKI-Tagung im Juni 1923). Nicht jede konterrevolutionäre Bewegung sei Faschismus, hieß es jetzt, und Clara Zetkin beispielsweise erklärte, der Horthy-Terror in Ungarn und der Faschismus seien „wesensverschieden”. „Der Faschismus ist der Sozialismus kleinbürgerlicher Massen", lautete die von Radek geprägte Formel; in den modernen Industriestaaten unterstützten ihn neben kleinbürgerlichen und -bäuerlichen Massen aber auch „unaufgeklärte proletarische Elemente". Deshalb müßten die Kommunisten ihn nicht in erster Linie „mit der Waffe in der Hand”, sondern vielmehr politisch und ökonomisch bekämpfen und seine Anhänger zum Kommunismus bekehren. „Wir müssen hinein in die kleinbürgerlichen Massen”, hieß die vor allem von Radek verkündete „Klassenstrategie des Proletariats". Dies erschien ihm als besonders wichtig deswegen, weil die deutsche Arbeiterklasse sich zwischen zwei Fronten befinde. ${ }^{1}$

In diesen Monaten überkreuzten sich, gipfelnd in den Wochen nach dem Scheitern des kommunistischen „Oktoberaufstandes” und des nationalsozialistischen "Novemberputsches”, zwei kommunistische Theorien über die Einschätzung des „deutschen Faschismus”. Die eine, vor allem von Sinowjew und seinen Anhängern vertretene, sah - in ziemlich einfacher Analogie mit der russischen Revolutionsgeschichte - im deutschen Faschismus einen „deutschen Koltschakismus", in General von Seeckt den ,deutschen Koltschak" und in „Hitler \& Co." „Marionetten" und „deutsche Purischkewitsch” ”, die wohl einige Verbindungen zum nationalistischen Kleinbürgertum besäßen, deren Programm jedoch „nicht real” sei, während sie selbst „mehr Narren und Spaßmachern als ernsthaften Politikern der Konterrevolution" glichen. ${ }^{2}$ Auf der anderen Seite versuchten Thal-

\footnotetext{
1 Der internationale Kampf des Proletariats gegen Kriegsgefahr und Faszismus. Protokoll der Verhandlungen der internat. Konferenz ... vom I 7.-21.3.1923, Berlin 1923, S. 28 (Zetkin); Inprekorr III, S. 95 I (Sinowjew), I003 f., 926 f. (Zetkin), IOI 3 f.: „Der Faschismus ist eine kleinbürgerliche Reaktion gegen die durch den Krieg geschaffene Lage, ... deren sich das Großkapital zur Wiederherstellung seiner Macht überall dort bedienen will, wo diese Macht gestürzt oder erschüttert ist." (Radek); ders. in: Die Rotc Fahne VI, Nr. 173 (29.7.1923, I.Beil.) und 176 (2.8.1923); Die Kommunistische Internationale [zit.KI] IV (1923), Nr. 24/25, S. 62 (G. Aquila), Nr. 27, S. 17 (Radek).

${ }^{2}$ Inprekorr III, S. 1540 (Sinowjew), x277f. (Radek); vgl. Die Lehren, a.a.O., S. 7 I: „Puriskewitsch ... war der russische Hitler” (Sinowjew). W.M. Purischkewitsch war ein an der Ermordung Rasputins im Dezember 1916 beteiligter Dumaabgeordneter der äußersten Rechten, ein Führer der „Schwarzhunderter”.
} 
heimer, Brandler und teilweise auch Radek, auf der Basis der Marxschen Interpretation in den „Klassenkämpfen in Frankreich" und im „I 8. Brumaire des Louis Bonaparte” eine soziologisch fundierte Einschätzung des Faschismus in Deutschland zu entwickeln. Marx hatte in seiner Analyse der französischen Ereignisse zwischen 1848 und I 85 I geschrieben, daß sich niemand mehr gegen die Kommunisten fanatisiere als der rettungslos am Abgrund des Bankrotts stehende Kleinbürger, daß beide „Mittelschichten” (Kleinbürger und Bauern) sich ungefähr in derselben Lage befänden und dazu neigten, sich unter bestimmten Umständen ,halb konservativen, halb revolutionären und ganz utopistischen Reformatoren" anzuschließen. Thalheimer meinte 1923, gegen Sinowjew sich wendend, historische Parallelen seien „schwierig zu handhaben"; die deutsche Situation sei nicht mit der im Rußland des Jahres 1917 zu vergleichen, Seeckt sei nicht der Rivale einer proletarischen Diktatur, sondern der Sieger über die bürgerliche Demokratie. Bereits Anfang 1923 hatte Brandler gewarnt, daß die zur Gefahr für die Arbeiterklasse gewordenen Nationalsozialisten sich auf von der Sozialdemokratie enttäuschte Arbeiter und auf die von den Folgen des verlorenen Krieges besonders stark betroffenen kleinbürgerlichen Schichten, denen ,die nationale Unterdrückung durch die Sieger" als Hauptquelle ihres Übels erscheine, stützen könnten. Die Rücksichtnahme der SPD auf das Kleinbürgertum erschien Thalheimer als „die wahre Quelle des Faszismus”. Wenn die deutsche Arbeiterklasse „aus ihrer Lähmung durch das sozialdemokratische Gift" erwachen werde, was vor allem von der kommunistischen Politik abhänge, dann werde der „Spuk des Faszismus” sich auflösen. Konsequent wurde als ,zentrale Aufgabe” der KPD „die Beschleunigung des Bankrotts der Sozialdemokratie, die revolutionäre Liquidierung dieses Bankrotts” gefordert. „Kommunismus oder Faschismus, ... Arbeiterregierung oder bonapartistische Diktatur" heiße letzten Endes die Alternative. Nur zeitweilig spiele die Bourgeoisie Sozialdemokratie und Faschismus gegeneinander aus; sobald die SPD die Verständigung mit Frankreich erreicht habe, solle der Faschismus das Proletariat unterwerfen. ${ }^{1}$

Auch der umstrittene „Schlageter-Kurs” sollte letzten Endes dem Ziel dienen, die kleinbürgerlichen Massen zu erreichen. Er führte

1 Marx-Engels, Werke, Bd. 7, Berlin 1960, S. 9-107, 27, 62, Bd. 8, S. i I x-207; Die Internationale VI (1923), S. 37-39 (Thalheimer?), I02 (dto.), 193 f. (dto.), sowie Die Rote Fahne VI, Nr. I60 (14.7.1923): „In Deutschland ist die Wendung der kleinbürgerlichen Massen zum Faschismus, d.h. an die Seite des Großkapitals, die direkte Folge des Verrats der Sozialdemokratie nicht nur an den Interessen der Arbeiterklasse, sondern auch der Mittelschichten ..." (Thalheimer); Inprekorr III, S. I54I (ders.); Rote Fahne, a.a.O., Nr. 23 u. 44 (Brandler). Vgl. K.H. Tjaden, Struktur und Funktion der „KPD-Opposition” (KPO), Meisenheim 1964, Bd. I, S. 28ff., 272-276. 
zwar zu einer Diskussion mit dem deutschvölkischen Führer Ernst Graf zu Reventlow, blieb jedoch zunächst ohne nachhaltigen Einfluß. ${ }^{1}$ Diese nationalistische Taktik ${ }^{2}$ sollte die den Sozialdemokraten gegenüber eingeschlagene Einheitsfrontpolitik ergänzen. Die Kommunisten hatten nämlich erkannt, daß „der politische Kampf gegen den Faschismus ... ohne die stärkste Hervorkehrung des nationalistischen Moments in unserer Propaganda unwirksam" war. ${ }^{3}$ Als einige Jahre später der Nationalsozialismus im Gefolge der Wirtschaftskrise seinen Siegeszug durch Deutschland antrat, wurde in veränderter Form (,Scheringer-Kurs”) auf die 1923 ausprobierte Taktik zurückgegriffen. Allerdings stand die Mehrzahl der KPD-Führer, die sie ursprünglich mit Radek ausgearbeitet hatten, inzwischen außerhalb der Partei.

Die kommunistische Politik gegenüber der SPD vor dem Scheitern des sogen. „Oktoberaufstandes” im Jahre 1923 war nicht einheitlich. Mit Befriedigung wurde festgestellt, daß die SPD abzusterben beginne und bereits aufgehört habe, "ein entscheidender aktiver Faktor des öffentlichen Lebens zu sein"; die konterrevolutionäre Kraft sei jetzt - im Gegensatz zu den Jahren I9I9/20 - bei den Faschisten konzentriert. Radek und die Brandler-Thalheimer-Führung der KPD setzten sich für ein Zusammengehen mit dem linken Flügel der Sozialdemokraten ein, während andererseits der ,reformistische” Einfluß auf das Proletariat als die „stärkste, aber auch die letzte Waffe des deutschen Großkapitals” bezeichnet wurde, „noch gefährlicher als selbst der Faschismus". Die linke Opposition unter Führung Ruth Fischers und Arkadi Maslows sprach sich dafür aus, die gesamte SPD und vor allem deren „sich herausbildenden linken Flügel” unerbittlich und scharf zu kritisieren. ${ }^{4}$ Im Gegensatz zu diesem „harten" antisozialdemokratischen Kurs wandte sich jedoch der Autor eines mit dem Titel „Sozialdemokratischer Faschismus" versehenen Artikels nicht gegen die deutsche Sozialdemokratie als solche, sondern nur gegen „, faschi-

\footnotetext{
1 Radek, „Leo Schlageter, der Wanderer ins Nichts”, in: Die Rote Fahne VI, Nr. 144; Sowjetstern oder Hakenkreuz? [Berlin 1923], S. 9 f. (Remmele). Vgl. : O.-E. Schüddekopf, Linke Leute von rechts, Stuttgart 1960, S. $146 \mathrm{ff}$; O. Wenzel, Die KPD im Jahre 1923, Diss. FU Berlin 1955, S. 98 ff.; W.T.Angress, Stillborn Revolution, Princeton UP 1963, S. 330 ff.; R. Fischer, Stalin und der deutsche Kommunismus, Frankfurt/M. [1950], S. 332. ${ }^{2}$ Vgl. J.W. Stalin, Werke, Bd. 6, Berlin 1952, S. I 34 ff., und Radek, Inprekorr III, S. I 172 : „Die Taktik, das sind die Maßregeln, die notwendig sind, um eine Schlacht zu gewinnen. Die Strategie ist die Gesamtheit der Maßregeln, die notwendig sind, um den Krieg zu gewinnen."

${ }^{3}$ Die Internationale VI, S. 426 (Böttcher); vgl. u.a. Tjaden, a.a.O., Bd. I, S. 28 f.; E.H. Carr, The Interregnum 1923-1924, London 1960, S. I59 ff.

4 Inprekorr III, S. II I 5-I7 (Radek, 3.8.), I 254 (H. Neumann, I 2.9.); Die Internationale VI, S. 259 ff., 290 (Thalheimer?); ebd. VII, Beilage zu Nr. 10/II, S. 25 (Resol.-entwurf des Berliner Zentralvorstands vom August 1923).
} 
stische Zellen" in der sozialistischen Jugendorganisation, die in den - bis zum Herbst 1924 von Karl Bröger redigierten - „Jungsozialistischen Blättern" ihr Sprachrohr gefunden hätten. ${ }^{1}$ Die sozialdemokratischen Arbeiter wurden aufgefordert, diese Anfänge im Keim zu ersticken.

Während wir uns bisher mit der „Vorgeschichte” des Begriffs „Sozialfaschismus" beschäftigt haben, nähern wir uns nunmehr der Zeit seiner Entstehung. Im Herbst 1923 endete die revolutionäre Periode in Mittel- und Westeuropa. ${ }^{2}$ Dieser Einschnitt wurde gekennzeichnet durch das Scheitern der kommunistischen Aufstandsversuche in Deutschland - Sinowjew verglich ihn im März 1926 mit der gescheiterten russischen Revolution von $1905^{3}$ - und in Bulgarien sowie des Hitlerputsches in München. Die Niederlage des Nationalsozialismus schätzten auch die deutschen Kommunisten als so entscheidend ein, daß unmittelbar nach dem 9. November 1923 etwa Emil Höllein prophezeite, damit habe die nationalsozialistische Bewegung als Macht, die die deutsche Zukunft bestimmen könnte, ausgespielt. „Aus Hitler wurde kein deutscher Mussolini." Die vor allem von Stresemann verkörperte „großkapitalistische Richtung im Faschismus” habe über die ,kleinbürgerliche" Richtung gesiegt. Es wurde behauptet, die Große Koalition (DVP, Zentrum, DDP, SPD) habe bereits ein „rein faschistisches Programm" aufgestellt und verwirklicht. Besonders tat sich hierin die bisherige Brandler-Thalheimer-Führung hervor. Die KPD-Zentrale stellte Anfang November 1923 fest, daß der Faschismus in der Person Seeckts in Deutschland gesiegt habe, - eine Behauptung, die Sinowjew und die „Linken” als Radeks „berüchtigte Novemberthesen” abtaten. Der Sinn dieser Formulierung vom Sieg des „Faschismus" in Deutschland war es nämlich, den Rückzug der KPD zu decken, während Sinowjew und die „Linken” um Ruth Fischer ihrerseits die Richtigkeit dieser Behauptung nicht zuletzt darum bezweifelten, weil sie dieses Manöver durchkreuzen wollten. ${ }^{4}$

${ }^{1}$ Inprekorr III, S. I ro3 f. (G. Hopffe).

${ }^{2}$ Die sowjetruss. Führung erkannte dies erst im Laufe d.J. I924voll an. So erklärte Stalin noch am 3.7.1924, daß „Deutschland mehr als jedes andere europäische Land mit der Revolution schwanger geht ..., und ein Sieg der Revolution in Deutschland bedeutet die Sicherung des Sieges der Revolution im internationalen Maßstab." (Stalin, a.a.O., Bd. 6, S. 238, vgl. Bd. 7, S. 29).

3 Protokoll. Erweiterte Exekutive der KI, Moskau 1 7.2.-1 5.3.1926, Hamburg-Berlin 1926, S. 495 .

4 Inprekorr III, S. I 477 f., vgl. I457, I454f., 1464, 1487 (Höllein), IV, S. I 5 I (A. Abusch); Protokoll. V. Kongreß der KI, I 7.6.-8.7.1924, [Hamburg 1924,] Bd. I, S. 66f. (Sinowjew); Die Internationale VII, S. I 8 (J. Sommer [-Winternitz]), 8 (Brandler): „Wie im Jahre 19 8 / I 9 die Bourgeoisie nur hinter dem Rücken der Sozialdemokratie in Gestalt der November- 
Im Winter 1923/24 wurde für den kommunistischen Mißerfolg vor allem die Sozialdemokratie verantwortlich gemacht und dabei in der KPD und Komintern die Theorie entwickelt, daß die sozialdemokratischen Führer, die durch ihren Verrat den „Faschismus” (d.h. Seeckt, Stresemann etc.) in den Sattel gehoben hätten, „auf Leben und Tod” bekämpft werden müßten: „Wer nicht zu brechen weiß mit den Wels, Müller und Ebert, den bewußten Werkzeugen des Faschismus, der ist selbst ein Werkzeug des Faschismus", hieß es auf der Parteiarbeiterkonferenz am 3. November 1923. Ganz ähnlich hiess es in einem Ende November im Reichstag verlesenen KPD-Aufruf, die SPD sei zum „Helfershelfer des Faszismus" geworden; wenn sie nicht mit dieser Partei brechen würden, so müsse „, der Kadaver der linken Sozialdemokraten heraus aus den Arbeiterreihen in die Kloake der Geschichte". Vor allem der Kominternvorsitzende Sinowjew, der bereits auf dem IV. Weltkongreß (r922) in der Sozialdemokratie den „schlimmsten Feind" gesehen hatte, prangerte sie als Helfershelfer des Faschismus an. Während jedoch, wie bereits erwähnt, Radeks, Thalheimers und Brandlers Angriffe auf die „durch ihr Paktieren mit dem Faschismus” diskreditierte SPD hauptsächlich von der Suche nach Schuldigen für die „Oktoberniederlage" bestimmt waren, wollten Sinowjew und die Linken in der KPD die scharfe Frontstellung gegen die Sozialdemokraten nicht zuletzt zur „Bolschewisierung”, zur Säuberung der KP von den Resten sozialdemokratischer Traditionen benutzen. ${ }^{1}$

Die beiden Richtungen in der Komintern- und KPD-Führung fochten ihre Meinungsverschiedenheiten, die nur auf dem Hintergrund des beginnenden Kampfes um Lenins Nachfolge in der Sowjetunion zu verstehen sind, vor allem auf der wichtigen Sitzung des EKKIPräsidiums im Januar 1924 aus. Einig waren sich beide Seiten in der scharfen Verurteilung der Sozialdemokratie. Brandler führte aus, der Gegner, die deutsche Bourgeoisie, habe mit Hilfe des „,kleinbürgerlichen Faschismus in Bayern" die Aufmerksamkeit von den Vorbereitungen zur faschistischen Machtübernahme ,in seiner schwerindustriellen und agrarkapitalistischen Gestalt durch Seeckt" ablenken können; der kampflose Sieg des Faschismus sei nur durch die Tolerie-

republik zur Herrschaft kommen konnte, so konnte der Faschismus 1923 nur versteckt hinter dem Rücken der linken und rechten VSPD.- und Gewerkschaftsbürokratie kampflos die Macht übernehmen."

1 Inprekorr III, S. 1457-60 (KPD-Konferenz); Verhandlungen des Reichstages, Stenogr. Berichte, Bd. 361, S. I 228 I (23.I x.1923); Protokoll IV. KI-Kongreß, S. 7, V. KI-Kongreß, a.a.O. (Sinowjew); Die Internationale VII, S. xo (Brandler). Vgl. die Bolschewisierungsthesen in: Thesen und Resolutionen. Erweiterte Exekutive (März/April 1925), Hamburg 1925, S. 7-47, sowie Radek (Die Lehren ..., a.a.O., S. I 8): „Die Ursache, warum ich für absolut nötig hielt, zu sagen, der Faschismus hat gesiegt, ist eine andere. Wenn der Faschismus gesiegt hat und die Sozialdemokratie sein Verbündeter ist, - kein Bündnis mehr mit der Sozialdemokratie."; Tjaden, a.a.O., I, S. $36 \mathrm{ff}$. 
rungspolitik der Sozialdemokratie möglich geworden. Er sah die Hauptgefahr darin, daß sich bei einer falschen kommunistischen Politik eine neue ,zentristische” Partei zwischen SPD und KPD bilden könne, die auch Zustrom aus den kommunistischen Reihen erhalten würde. Sinowjew teilte mit, Anfang Oktober 1923 sei in Moskau in Anwesenheit der KPD-Vertreter beschlossen worden: „Der Hauptfeind ist die linke Sozialdemokratie; wir müssen verstehen, daß wir den Kampf führen müssen nicht nur obne, sondern gegen die linken Sozialdemokraten.” Jedes politische Bündnis mit dieser Partei, die das schwankende Kleinbürgertum repräsentiere und zu einem „Flügel des Faschismus”, zu einer "faschistischen Sozialdemokratie” geworden sei, erklärte er nunmehr für unmöglich. Diese Einschätzung der sozialdemokratischen Führer als einer „Fraktion des deutschen Faschismus unter sozialistischer Maske" setzte sich durch, wie die am 19. Januar 1924 verabschiedete EKKI-Resolution über die „Lehren der deutschen Ereignisse" zeigte, in der auch die Einheitsfronttaktik modifiziert und die linken SPD-Führer für "noch gefährlicher" als die rechten erklärt wurden. Sinowjew hielt sie für die „letzte historische Maskerade" der Sozialdemokratie; er meinte, entweder werde die „faschistische Bourgeoisie” mit der Unterstützung der sozialdemokratischen Führer oder die KPD siegen. In Deutschland sollte nun strikt die ,Einheit von unten” angestrebt werden. ${ }^{1}$

Damit begann ein scharfer Linkskurs der KPD, der innerparteilich eine verstärkte „Bolschewisierung” mit sich brachte. Offiziell eingeleitet wurde er auf dem illegal stattfindenden IX. KPD-Parteitag im April 1924, auf dem die linke Fraktion unter Leitung Ruth Fischers und Arkadi Maslows die Führung erhielt. Der Wahlsieg bei den Reichstagswahlen im Mai 1924 (die KPD erhielt 3,7 Millionen, die SPD 6 Millionen Stimmen) wurde als Bestätigung der Richtigkeit der neuen Politik der „Mobilisation der Massen von unten her” aufgefasst. Maslows Forderung lautete: „Die Vernichtung der Sozialdemokratie als Partei ist das nächste Ziel nach dieser Richtung." Die gegenwärtige Funktion der deutschen Sozialdemokratie sei es, ,die Partei der bürgerlichen Demokratie zu sein”, durch ihren Masseneinfluss die „Diktatur der Kapitalsmagnaten" zu schützen. Diesem Ziel solle auch, wenn die SPD eine neue Koalition mit den bürgerlichen Parteien erreiche, das Reichsbanner dienen, angeblich eine „aus Kleinbürgern gebildete Truppe”, eine „Faschistentruppe” zur Bekämpfung aller Angriffe gegen diese Diktatur. Der damals zu den „Ultralinken”gehörende Arthur Rosenberg forderte ebenfalls zum Kampf gegen den „schwarz-

1 Die Lehren ..., S. 33, 37 (Brandler), 60f., 66 ff. (Sinowjew), ro5-107 (Resolution); KI V (1924), Nr. 3r/32, S. 22of. (Sinowjew). Vgl. die Thesen u. Erklärungen der drei KPDFraktionen in: Die Internationale VII, Ergänz.-heft Nr. I (Januar I924). 
rotgoldenen Faschismus" dieser republikanischen Wehrorganisation auf. 1

Parallel zu diesem bis in das Jahr 1925 hinein andauernden scharfen Linkskurs der KPD ging eine ebensolche Politik der Kommunistischen Internationale. Der V. Kominternkongress im Juni/Juli I924 proklamierte die Sozialdemokratie zur „dritten” Partei der Bourgeoisie. Sinowjew erklärte abermals, es sei „eine wichtige politische Tatsache”, daß die Sozialdemokratie ,zu einem Flügel des Faschismus geworden ist”. Sie stelle sich genauso wie dieser der Bourgeoisie „,im erwünschten Augenblick als offene Kampforganisation der Konterrevolution" zur Verfügung, ihre Regierungsbeteiligung vergrößere nur die Kriegsgefahr, denn „die konterrevolutionären Führer der Sozialdemokratie werden sich in ihrem grenzenlosen $\mathrm{Haß}$ gegen die Sowjetmacht eher $\mathrm{zu}$ Kriegsabenteuern entschließen als selbst mancher offenherzige Bourgeois". In den vom Kongreß verabschiedeten Thesen hieß es, bei der fortschreitenden Zersetzung der bürgerlichen Gesellschaft nähmen alle bürgerlichen Parteien, vor allem die sozialdemokratischen Parteien, einen mehr oder weniger faschistischen Charakter an. Sozialdemokratie und Faschismus seien lediglich "die beiden Seiten ein und desselben Werkzeuges der großkapitalistischen Diktatur", darum könne die Sozialdemokratie kein zuverlässiger Bundesgenosse im Kampf gegen den Faschismus sein. ${ }^{2}$

Anknüpfend an diese Verurteilung der Sozialdemokratie stellte Stalin im September 1924, also gleichzeitig mit der Theorie vom Aufbau des Sozialismus in einem Lande, seine These von der Zwillingsbrüderschaft von Faschismus und Sozialdemokratie auf, die Trotzki später so höhnisch kritisiert hat. Stalin behauptete, daß weder die Faschisten noch die Sozialdemokraten ohne gegenseitige Unterstützung entscheidende Erfolge erzielen könnten: „Der Faschismus ist eine Kampforganisation der Bourgeoisie, die sich auf die aktive Unterstützung der Sozialdemokratie stützt. Die Sozialdemokratie ist objektiv der gemäßigte Flügel des Faschismus. ... Diese Organisationen schließen einander nicht aus, sondern ergänzen einander. Das sind keine Antipoden, sondern Zwillingsbrüder." Diese Sinowjews Einschätzung

\footnotetext{
1 Die Internationale VII, S. 297, 419 (Maslow), 677-683, 681 (Rosenberg): „Der Ludendorff-Faschismus mußte ersetzt werden durch den Marx-Stresemann-Faschismus. Dic schwarzweißroten Stoßtrupps mußten ersetzt werden durch schwarzrotgoldene Stoßtrupps. ... Man kann die SPD, wie sie in Deutschland seit der Revolution Politik machte, umschreiben als eine pazifistisch-demokratische Partei für Arbeiter." Vgl. ebd. VIII, S. 12 (Rosenberg). Für R.s spätere Beurteilung s. bes.: Historikus, Der Faschismus als Massenbewegung, Karlsbad 1934, S. 40-63.

2 Protokoll V. KI-Kongteß, S. 64, 67 (Sinowjew), vgl. 396 f. (Bordiga); Thesen V. KIKongreB, a.a.O., S. 15, 17, 121 .
} 
wiedergebende „Theorie”, die nicht zuletzt als Ausdruck der sowjetrussischen Enttäuschung über das Ausbleiben der erhofften Revolution in West- und Mitteleuropa zu verstehen ist, schloß streng genommen jeden späteren Rückgriff auf eine „Einheitsfronttaktik von unten und von oben" mit den Sozialdemokraten aus. Einige Jahre später wurde sie die Basis der Losung vom „Sozialfaschismus". ${ }^{1}$

Diese taktisch bedingte Ausweitung des Begriffs „Faschismus” war schon vorbereitet worden in der vom V. Kominternkongreß beschlossenen „Resolution über den Faschismus”, in der dessen grundlegende Definition enthalten ist. In ihr wurde der Faschismus als „eine der klassischen Formen der Konterrevolution in der Verfallsepoche der kapitalistischen Gesellschaftsordnung" bezeichnet; er entstehe vor allem dort, wo das Proletariat den Machtkampf aufgenommen, aber nicht erfolgreich geführt habe. Als Maßnahmen zur Bekämpfung dieser ihrer sozialen Struktur nach überwiegend kleinbürgerlichen Bewegung wurden aufgezählt: „Eine wirklich revolutionäre Strategie und Politik der kommunistischen Parteien", die "Anstrebung der Einheitsfront aller arbeitenden Schichten”, natürlich im Sinne einer „Einheitsfront von unten”, die „Organisierung des Generalstreiks”, die "Anwendung des Massenterrors ... durch Repressalien gegen die Faschisten" (erinnert sei in diesem Zusammenhang an die spätere Parole „Schlagt die Faschisten, wo ihr sie trefft!”) und die „Vertreibung der Faschisten aus den Betrieben”. ${ }^{2}$ Viele dieser Forderungen hatten, sollten sie mit der Aussicht auf Erfolg in die Tat umgesetzt werden, zur Voraussetzung, daß die Kommunisten bereits die entscheidenden Teile der Arbeiterschaft gewonnen hatten und außerdem Staatsapparat und Wirtschaftsorganisation schwach und unsicher geworden waren.

Auch im Jahre I925 wurde der nachdrückliche Kampf gegen die SPD zunächst noch fortgesetzt; allerdings wurde sie jetzt kaum noch als

\footnotetext{
${ }_{1}$ Stalin, a.a.O., Bd. 6, S. 253, vgl. 379 (über unpubliz. Brief vom x6.I1. an das ZK der KPD). Vgl. L. Trotzki, Was nun?, Berlin 1932, S. 19: „Wie bei Stalin üblich, sobald er versucht zu verallgemeinern, widerspricht der erste Satz dem zweiten. Daß Bourgeoisie sich auf die Sozialdemokratie stützt und der Faschismus eine Kampforganisation der Bourgeoisie darstellt, ist völlig unbestreitbar... Wie dabei die Sozialdemokratic überdics noch den ,Flügel' des Faschismus bildet, ist nicht zu verstehen. Auch die zweite Feststellung ... ist nicht viel tiefsinniger :... Zwillinge können erbitterte Gegner sein; andererseits müssen Verbündete keinesfalls am gleichen Tag von einer gemeinsamen Mutter geboren sein. Stalins Konstruktion gebricht es selbst an formaler Logik, von Dialektik nicht zu reden. Die Kraft dieser Konstruktion besteht darin, daß niemand ihr widersprechen darf."
}

2 Thesen V. KI-Kongreß, S. I 2 I-I 23. Vgl. M.[ünzenberg] Willi, Die Entwicklung und der Stand der faschist. Bewegung Frühjahr r924, Berlin (1924), S. 3r ff., 56. 
„faschistisch” bezeichnet. Rosenberg, mit Werner Scholem der Führer einer der ,ultralinken" Gruppen, nannte zwar immer noch das Reichsbanner „ein neues, modernes und (den Wünschen der „Bourgeoisie” gegenüber. S.B.) völlig gefügiges Faschistenheer”, aber auch er erklärte nun, daß der sogenannte „schwarz-weiß-rote Faschismus” die eigentliche Stütze der die Staatsmacht ausübenden „Großbourgeoisie" sei. Was Rosenberg damals darunter verstand, zeigt, daß für ihn der „Faschismus” beim Zentrumsführer Adam Stegerwald begann. Wenn er beklagte, daß die SPD ,so und so viele Millionen Arbeiter" dem Kommunismus entziehe, so bedeutete dieses Eingeständnis im Grunde eine Anerkennung der Tatsache, daß es sich bei der damaligen deutschen Sozialdemokratie nicht einfach um eine „konservative bürgerliche Partei" handelte. J. Lenz (alias Winternitz) sprach sich auf der „2. Reichstagung des Marxistisch-Leninistischen Zirkels” in Weimar am 31. 5. und I. 6. I925 besonders deutlich gegen die Fortsetzung der bisherigen Taktik aus, weil „das den Einfluss der SPD stabilisiert”. Wolle man die bisher noch von einer „Fraktion der Bourgeoisie, der SPD" geführte ,demokratische Fraktion", der die Mehrheit des Proletariats und ein Teil des Kleinbürgertums angehöre, in den Einflussbereich der KPD bringen, so müsse man damit beginnen, ihr ein gemeinsames Vorgehen gegen die Reaktion vorzuschlagen. In einer Anfang I 926 erschienenen autoritativen kommunistischen Darstellung wurden übrigens nur ca. 30\% der SPD-Mitgliedschaft dem „Kleinbürgertum”, der Rest dem „Proletariat" zugerechnet. ${ }^{1}$

Das EKKI sandte im Juli I 925 einen von Sinowjew unterzeichneten Brief an den X. KPD-Parteitag, in dem der Partei vorgeworfen wurde, daß nicht zuletzt ihre Fehler die SPD gestärkt hätten. Die Sozialdemokratie sei und bleibe die „dritte Partei der Bourgeoisie”, ein "Flügel des modernen Faschismus", hieß es, und für Deutschland proklamierte das EKKI die „Liquidierung des Einflusses der konterrevolutionären Sozialdemokratie auf die proletarischen Massen" zur wichtigsten Frage der Revolution. Auf dem Parteitag wurde in den „Thesen zur Lage und zu den Aufgaben der KPD” verkündet, „daß die Sozialdemokratie und die mit ihr verbündete Gewerkschaftsbüro-

\footnotetext{
1 Die Internationale VIII (1925), S. I55f. (Rosenberg), 57 (Lenz-Winternitz); Protokoll der 2. Reichstagung des Marxist.-Leninist. Zirkels, (Berlin 1925), S. 51,54 (Lenz); Die Sozialdemokratischen Parteien. Hrsg. E. Varga, 2. Aufl. Hamburg 1926, S. 42 f., $47 \mathrm{ff}$. (allerdings wurde diese Angabe als "etwas mechanisch" bezeichnet, da sich unter den als „Kleinbürger” Eingestuften „,noch viele Proletarier” befänden); vgl. Jb.f.Wirtschaft, Politik und Arbeiterbewegung 1925/26, Hamburg 1926, S. 759, und R.N.Hunt, German Social Democracy, I918-I933, Yale UP 1964. Sinowjew meinte auf dem VI. EKKIPlenum Protokoll, S. 55f.; S. 22 I, Anm. 2, die SPD werde immer mehr zu einer Partei der „Arbeiteraristokratie”.
} 
kratie das festeste Bollwerk der Bourgeoisie sind, das den Vormarsch der Arbeiterklasse bewußt hemmt und ihren Kampf und Sieg bewußt vereitelt". Diese antisozialdemokratischen Stellungnahmen änderten aber nichts daran, daß die kommunistische Politik teilweise bereits revidiert worden war. Auf dem Gewerkschaftsgebiet wurde schon seit dem Sommer 1924 gegen die „linke” Austrittspolitik der „Kampf um die Einheit” und um die „Eroberung der Gewerkschaften” proklamiert. ${ }^{1}$ Und Ruth Fischer vertrat zwar auf dem X. Parteitag die Ansicht, daß die „bankrotte” Sozialdemokratie immer auf Arbeiter schieße; trotzdem sprach sie sich - ebenso wie Sinowjew Anfang April - nicht mehr grundsätzlich gegen eine „Einheitsfronttaktik von unten und von oben" und zeitweilig (vor allem auf der Zentralausschußsitzung im Mai I925) sogar für einen „Volksblock” aus. Diese Schwenkung begründete sie mit einer Situationsänderung seit dem Frühjahr i 924. ${ }^{2}$ Ernst Thälmann, kurz vorher als KPD-Kandidat bei den Reichspräsidentenwahlen bekannt geworden, nahm Ruth Fischer damals noch gegen die ,ultralinken” Angriffe in Schutz. An ihre Behauptung, der linke Flügel der deutschen Sozialdemokratie zeichne sich durch einen besonders großen Kommunistenhaß aus, knüpfte Fischer übrigens die Bemerkung, daß dieser linke Flügel auch die Funktion habe, das „verbindende Glied” zwischen den ,techten” und den ,ultralinken" Kommunisten zu sein. ${ }^{3}$

Unmittelbar nach diesem von Bucharin kurz darauf als „tot" bezeichneten Parteitag setzte der Angtiff des EKKI auf die KPDFührung ein, der u.a. vorgeworfen wurde, sie habe eine „Zigeunerpolitik" geführt und die sozialdemokratischen Tendenzen in der Partei angestiftet statt bekämpft. ${ }^{4}$ Der Angriff endete mit der Einset-

1 Bericht über die Verhandlungen des X. Parteitages der KPD. Berlin vom I 2.-1 7.7.1925, Berlin 1926, S. 172 ff. (EKKI-Brief), 199 (Thesen); Beschlüsse, Resolutionen und Aufrufe des 3. Kongresses der RGI, Moskau 8.-21.7.1924, (Berlin) I924.

2 Protokoll X. KPD-Parteitag, S. 495, 506 ff. (Fischer); Protokoll VI. EKKI-Plenum, S. 74f. (Scholem), I7I (Fischer); vgl. Die monarchistische Gefahr und die Taktik der $\mathrm{KPD}$, (Berlin 1925): ,Wir können nicht als Arbeiterpartei sagen, um gewisse Fragen, wo es sich um eine politische Deklaration handelt, sind diese zwei Gruppen, Sozialdemokratie und Bürgertum, gemeinsame Feinde. Wenn es sich darum handelt, ob bürgerliche Demokratie oder Monarchie, müssen wir Unterschiede machen." (Sinowjew, 2.4.1925, zit. Fischer, a.a.O., S. 513), sowie Die Internationale VII, S. 500 (Fischer).

3 Protokoll X. KPD-Parteitag, S. 634 (Thälmann), 508 (Fischer), vgl. 545 ff. (Rosenberg), $557 \mathrm{ff}$. (Scholem). - Zur Terminologie vgl. VI. EKKI-Protokoll, S. $57 \mathrm{ff}$. (Sinowjew), 254f. (Zetkin), 75 (Scholem): „Ich muß ... die Frage aufwerfen, wie eigentlich jetzt Gen. Sinowjew die Terminologie des Wortes ultralinks benutzt. Ursprünglich entdeckte man das Wort, um zum Ausdruck zu bringen: es gebe eine anständige kominterntreue Linke und anderseits eine ungesunde kominternfeindliche Ultralinke. Ich habe ... in der Rede Sinowjews gehört, daß jetzt die gesamte Linke als Ultralinke bezeichnet wird... Wenn man jetzt das Wort links fallen läßt und ultralinks gleich links setzt, so ist alles in Ordnung." 4 Der neue Kurs, Berlin 1925, S. 11, 9, 5 (Bucharin). 
zung eines neuen Zentralkomitees unter Thälmanns Führung auf der I. Reichsparteikonferenz am 31.10./1.I I.I925. Die gemäßigte „Einheitsfronttaktik von unten und von oben" wurde daraufhin konsequenter durchgeführt. Sie fiel zusammen mit der Politik des „Aufbaus des Sozialismus in einem Lande" und der Ausschaltung der trotzkistisch-sinowjewistischen Opposition in der Sowjetunion. Die Einheitsfrontpolitik der KPD bei der Fürstenenteignungskampagne 1926 sollte vor allem die SPD-Führung „entlarven” und das „schwarzrotgoldene Bündnis" zwischen SPD, DDP und Zentrum sprengen. Unter Wahrung der „Hegemonie der KPD” sollte, wie das Polbüromitglied Arthur Ewert schrieb, jetzt der linke Flügel der Sozialdemokratie ,in jedem ernsthaften Scbritt gegen die Politik ihres Parteivorstandes" von den Kommunisten unterstützt werden. ${ }^{1}$

Die kommunistische Haltung gegenüber den „Reformisten” oder "Sozialimperialisten”, wie die Sozialdemokraten nunmehr wieder häufiger genannt wurden, war das ganze Jahr 1926 hindurch von dem Bestreben geleitet, die sozialdemokratischen Führer zu Konzessionen zu zwingen. Auf dem VI. EKKI-Plenum trat Thälmann beispielsweise für einen gemeinsamen Kampf des Roten Frontkämpfer-Bundes mit den „Kameraden des Reichsbanners” gegen den Faschismus ein, und Sinowjew, dessen Stellung bereits erschüttert war, sprach sich zwar gegen eine Revision der die Sozialdemokratie betreffenden Beschlüsse des V. Weltkongresses aus, verurteilte aber doch die ,Vulgarisierung" der Thesen, deren sich alle Gruppierungen in der KP, die Rechten wie die Linken, schuldig gemacht hätten. Er wie auch der RGI-Generalsekretär Losowski beschuldigten vor allem die „linke” KPD-Führung unter Ruth Fischers Leitung, sie habe ein feindliches Verhältnis zwischen Sozialdemokraten und Kommunisten gezüchtet. Auch jetzt noch sei die „Kultivierung feindseliger Beziehungen” zwischen sozialdemokratischen und kommunistischen Arbeitern ein wunder Punkt vor allem in Deutschland; wer nicht begreife, daß eine derartige Taktik ,das beste Geschenk für die Bourgeoisie" sei, sei kein Kommunist (!). Man müsse „unrichtige Formulierungen” über die Notwendigkeit eines kommunistischen Klassenkampfes gegen die Sozialdemokraten bekämpfen und stattdessen berücksichtigen, daß die KP wohl einen Klassenkampf gegen die Bourgeoisie, mit der Sozialdemokratie und der Gewerkschaftsbürokratie jedoch einen Kampf um die Ar-

1 Die Internationale IX (1926), S. 66 (P. Frölich), I93 f. (K. Schmidt), Ior, 98 (A. Ewert) : „Einen Kampf für die Klassenforderungen des Proletariats aber kann die SPD - selbst wenn ihre Arbeitermitglieder dies wollen - nicht führen. Ihre Leitung wird stets die Einheitsfront zu sprengen versuchen." Vgl. H. Karl, Die deutsche Arbeiterklasse im Kampf um die Enteignung der Fürsten (1925-1926), Berlin 1957. 
beiterklasse führe. Bucharin erklärte nachdrücklich, daß die Existenz mächtiger sozialdemokratischer Parteien und Gewerkschaften eine kommunistische Einheitsfronttaktik erforderlich mache. ${ }^{1}$ Der italienische KP-Führer Togliatti schließlich wandte sich auf Grund der italienischen Erfahrungen gegen die Zweifrontentheorie „Klasse gegen Klasse" (ohne diese Formel zu erwähnen). Er wies darauf hin, $\mathrm{da} ß$ der Kommunismus es mit zwei verschiedenartigen Feinden zu tun habe, dem im großbürgerlichen Dienst stehenden Faschismus ${ }^{2}$ und dem kleinbürgerlichen Block, dem die Sozialdemokratie zuzurechnen sei; diesen beiden feindlichen Gruppierungen gegenüber müsse man auch verschiedenartige Taktiken anwenden. ${ }^{3}$ Sinowjew, der im Grunde genommen an der antisozialdemokratischen Taktik festhalten wollte, wertete eine unglückliche Formulierung Friedrich Stampfers im Reichstag als Beweis dafür, „daß die Führerschaft der Sozialdemokratie und des Faschismus nicht allzu weit voneinander entfernt" seien; "stellenweise” bestehe sogar „keinerlei Unterschied” zwischen ihnen. ${ }^{4}$

Auf dem VII. EKKI-Plenum Ende I 926 bekräftigte der inzwischen abgesetzte Sinowjew diese Stellungnahme nochmals, während Bucharin, sein Nachfolger als Kominternvorsitzender, wiederum die Wichtigkeit einer „Einheitsfront des ganzen Proletariats” als Voraussetzung für einen „erfolgreichen Kampf gegen die kapitalistische Offensive” hervorhob, allerdings unter Einschluss „schonungsloser Kritik” an den Sozialdemokraten und der "Entlarvung jedes reformistischen Verrats". Kuusinen beklagte die in Deutschland besonders starke

1 Protokoll VI. EKKI-Plenum, S. 197f. (Thälmann), 48-52 (Sinowjew), 465, 340, 473 (Losowski), 228 (Bucharin), vgl. 465 (Losowski): „Es hat in Deutschland Parteiorganisationen gegeben, die Beschlüsse faßten, daß Parteimitglieder sich nicht mit Sozialdemokraten unterhalten dürften. Das scheint ungeheuerlich, ist aber doch eine Tatsache."

2 Auf dem Plenum sagte Bracco: „Man muß sich darüber klar sein, daß der Faschismus nicht die Form einer beliebigen Reaktion ist, sondern der moderne Typus der gegen die Arbeiterklasse gerichteten Reaktion, welche eine Zeit erbitterter Kämpfe zwischen dem Proletariat und der Bourgeoisie zur Voraussetzung hat." (S. 448).

3 VI. EKKI-Protokoll, S. 2 I 5-226 (Ercoli[-Togliatti]).

4 Ebd., S. 50; vgl. Verhandlungen des Reichstags, Stenograph. Berichte, Bd. 388, S. 5368 : „Es gibt ja ... Leute, die glauben, da 3 auch uns und daß ganz Eutopa eine mussolinische Ära bevorsteht. ... Ich für mein Teil glaube an diese mussolinische Ära Europas nicht. Es ist ja das tragikomische Mißgeschick des Faschismus aller Länder, daß er immer nach einem Führer schreit und keinen findet. Wenn der Faschismus einen Führer braucht, dann muß er warten, bis ein Sozialist verrückt geworden ist. ... Dann hat er einen. (Zuruf rechts.) - Warten Sie nur, vielleicht haben Sie auch einmal das Glück. Mit den eigenen Mitteln schaffen Sie es nun und nimmer. (Heiterkeit links.) Ich glaube aber an die kommende mussolinische Ära Deutschlands auch deshalb nicht, weil wir unsere mussolinische Ära schon hinter uns haben. (Heitere Zustimmung bei den Sozialdemokraten.)" (Stampfer, 9.2.1926). 
Isolierung der KP von den Massen. ${ }^{1}$ Im ganzen gesehen trat die Beschäftigung mit der Sozialdemokratie und der Kampf gegen sie jedoch in den Hintergrund. KPD und Komintern waren zu sehr mit ihren eigenen Problemen beschäftigt, dem Abschluß der „Bolschewisierung” und dem Kampf gegen die Linksopposition. SPD und KPD rangen in relativ gemäßigter Form mit- und gegeneinander um die Vergrößerung ihres politischen Gewichts, wobei natürlich die heftigen Auseinandersetzungen der vorhergegangenen Jahre nachwirkten. ${ }^{2}$

Ihre zurückhaltende Einheitsfrontpolitik trug der KPD-Führung von den „Ultralinken” den Vorwurf ein, sie liquidiere den Kommunismus und führe die KP zur Sozialdemokratie zurück. Es hieß, die KPD sei im Grunde genommen bereits jetzt eine zweite sozialdemokratische Partei. $^{3}$ In ihrer Polemik gegen die Parteiführung bezeichneten die Linksoppositionellen Ende 1927 RFB-Mitglieder, die Versammlungen der Opposition störten, als „Sozial-Faschisten”. Wenig später wurden die "ultralinken" Führer ihrerseits von der KPD „Sozialfaschisten” und Konterrevolutionäre genannt. ${ }^{4}$ Die heftigen Angriffe von links hatten zur Folge, daß die KPD-Führung ihr Festhalten am Kommunismus zu unterstreichen versuchte. Bezeichnend dafür waren die Diskussionen auf dem XI. Parteitag im März 1927. Zwar wandte sich dort Ernst Meyer gegen eine Wiederholung der falschen antisozialdemokratischen „Prügeltaktik" aus der Zeit Ruth Fischers, die die SPD nicht geschwächt, sondern vielmehr gestärkt habe. Und noch weiter ging der ehemalige „Ultralinke” Rosenberg, der es für wichtiger hielt, die linken Abweichungen innerhalb des Kommunismus zu bekämpfen als die rechten, und daran etinnerte, daß der größte Teil der kommunistischen Anhängerschaft entweder in Kleinbetrieben arbeitete oder arbeitslos war, so daß die KPD tatsächlich nur ,an der Peripherie der Arbeiterklasse" stand. In den vom Parteitag verabschiedeten Thesen wurden dagegen die linkssozialistischen Führer „der Hauptfeind der Arbeiterbewegung” genannt, da sie die „letzte

${ }_{1}$ Protokoll. Erweiterte Exekutive der KI, Moskau, 22.I I.-I6.I 2. I926, Hamburg-Berlin 1927, S. 563 f. (Sinowjew), I 44 (Bucharin), I37f. (Kuusinen), vgl. 255 (Zetkin).

2 Z.B. soll nach Ulbrichts Behauptung in einem sozialdemokratischen Rundschreiben gefordert worden sein: "Soll der Kampf gegen den Hauptgegner von rechts erfolgreich sein, muß zunächst die größtmöglicbe Scbwacbung der KPD herbeigefühtt werden." (Inprekorr V, S. I $154-56$ ).

3 Vgl. z.B.: Reichstagsprot. Bd. 393,'S. I 1043 ff. (R. Fischer, 24.6.1927), I I $228 \mathrm{ff}$. (H. Urbahns), sowie von „rechts” Rosenberg, S. I I $18 \mathrm{I}$ : „Es ist ... absolut nicht so, daß die offizielle KPD irgend eine reale Gefahr für den bestehenden Staat bedeutet. ... Was übrig bleibt, ist nur eine gewisse romantische Phraseologie..."; Die Fahne des Kommunismus I (1927), S. 29: „Wer annimmt, Reformisten könnten und würden je etwas anderes tun, als die Arbeiterbewegung sabotiren, der ist selber ein Reformist und Liquidator."; Vih.f. Zeitgesch. IX (196I), S. 359-383 (Bahne).

4 Fahne des Kommunismus I, S. 203, II, S. 258. 
Barriere" für den Übergang der unzufriedenen Massen zum Kommunismus bildeten. ${ }^{1}$

Die Bezeichnung „Sozialfaschismus" war bereits im Frühjahr 1926 anlässlich der Gründung der ASPD in Sachsen auf die Führer der neuen rechtssozialdemokratischen Partei (Buck, Winnig, Heldt, Niekisch u.a.) angewandt worden, verknüpft mit der Behauptung, dass sie allerdings nichts anderes täten als die SPD-Führer in früheren Jahren. 1927 erklärte Thälmann, die Altsozialdemokraten ständen ,in der Mitte zwischen Sozialdemokratie und Faschismus" und zeigten „die Berührungspunkte des Faschismus mit der Sozialdemokratie”. In dieser Beurteilung stimmten die "Rechten" und die „Stalinisten” miteinander überein; der wichtigste Differenzpunkt war, daß „rechte” Funktionäre wie Jakob Walcher und Paul Böttcher die linkssozialdemokratischen Führer im Rahmen einer verstärkten Einheitsfronttaktik zum gemeinsamen Kampf gegen die „reformistischen Sozialimperialisten", deren Politik viel Gemeinsames habe mit der faschistischen Ideologie der Klassenversöhnung, auffordern wollten. Heftiger noch als die SPD-Funktionäre wurden vielfach die „reformistischen” Gewerkschaftsfunktionäre angegriffen. ${ }^{2}$

Diese relativ gemäßigte kommunistische Taktik wurde 1928 durch eine Linkswendung beendet, die sich im folgenden Jahr zu einer „ultralinken” Taktik auswuchs. Die Gründe für die Ânderung der kommunistischen Politik müssen nicht zuletzt in der Verschlechterung der inneren Situation in der Sowjetunion gesucht werden. Vermutlich vor allem, um die kapitalistischen Staaten von einem Eingreifen abzuhalten, begannen die Kominternsektionen mit der Durchführung einer radikalen Politik. Diese schloß eine scharfe Frontstellung gegen die Sozialdemokratie ein, der Anhänger abspen-

1 Bericht über die Verhandlungen des XI. Parteitages der KPD, Essen vom 2.-7.3.1927, Berlin 1927, S. 103 (Meyer), 202 f. (Rosenberg), r6 63 f., 58-60 (Thälmann), vgl. 386 (F. Heckert); Thesen und Resolutionen des XI. Parteitags der KPD, Berlin I927, S. I6ff. Demgegenüber hatte J. Walcher in der Internationale (X, S. $325 \mathrm{f}$.) gemeint, es sei "unsinnig", die linke Sozialdemokratie als den Hauptfeind zu bezeichnen. Vgl. seine Kontroverse mit M. Osten (B. Lominadse) ebd., S. 208-220, 325-344, sowie Tjaden, a.a.O., I, S. 68,64

2 Protokoll XI. Parteitag, S. 57 f. (Thälmann); Faschismus in Deutschlandl?, Berlin (1927), S. 20; Die Internationale IX, S. 32 I f. (Ewert), 327 (Ph. Dengel), 264 (F. Rück), 438 (Böttcher), ebd. X, S. 492-498 (Böttcher, „Sozialimperialismus und Sozialfaschismus in den Gewerkschaften”), 37I ff. (K. Becker), 253 (E. Kunik): „Vor dem Tertorismus der Hitler-Garden stand der Terrorismus der Noske-Garden, und die antidemokratische Grundeinstellung aller faschistischen Organisationen deckt sich fast völlig mit der antidemokratischen Praxis der reformistischen Gewerkschaftsführer."; Inprekorr VI, S. 136rf. (Dengel), vgl. 345 f. (Neubauer), I242f. (P. Dietrich); Rotes GewerkschaftsBulletin VIII (1928), S. I92. 
stig gemacht werden sollten und die überdies als möglicher Initiator oder Unterstützer eines Interventionskrieges gegen Sowjetrußland betrachtet wurde. Die Sozialdemokratie, so hieß es im Sommer 1928 etwa, habe diesmal ihren 4. August schon vor dem Ausbruch eines neuen Krieges gehabt. ${ }^{1}$ Und 1932 zog der außenpolitische Experte der kommunistischen Reichstagsfraktion, Theodor Neubauer, aus der Behauptung, da $\beta$ die deutschen Imperialisten nur mit Hilfe der Sozialdemokratie die Arbeitermassen in den Dienst ihrer Außenpolitik stellen könnten, die bezeichnende Schlußfolgerung: „Wer darum diese Außenpolitik der deutschen Kapitalistenklasse bekämpfen will ..., der wird die Sozialdemokratie als die Stütze dieser Außenpolitik mit derselben Schärfe bekämpfen müssen."2

$\mathrm{Zu}$ den vielen „ultralinken" Losungen, die nunmehr von den linksoppositionellen Kommunisten übernommen wurden, gehörten die von der selbständigen revolutionären Streiktaktik gegen den Willen der „reformistischen Gewerkschaftsbonzen” und die Parole „Klasse gegen Klasse”; hinzu kam die Anwendung der Bezeichnung „Sozialfaschisten" auf die Sozialdemokraten. Diese taktische Wendung war Ende 1927 beschlossen worden. Ein Aufsatz des Leiters der Revolutionären Gewerkschaftsopposition (RGO) Paul Merker im Februarheft 1928 der „Internationale"3 gehörte zu den ersten Anzeichen für die Änderung der Taktik in Deutschland. In ihm wurde indirekt die Führung ,politischer Massenkämpfe oder ökonomischer Kämpfe mit entscheidenden politischen Konsequenzen" auch ohne die Zustimmung der Gewerkschaftsführer gefordert, im Gegensatz zur bisheiigen Losung „Zwingt die Bonzen!”. Merker forderte, man müsse den Kampf gegen die „Reformisten” mit viel größerem Elan und viel mehr Kühnheit, ohne Furcht vor den unvermeidlichen Opfern, führen. Wie die neue Taktik allmählich eingeführt wurde, zeigen die Verhandlungen des IX. EKKI-Plenums im Februar, des IV. RGI-Kongresses im März und des VI. Kominternkongresses im Sommer 1928. Diese gegen den Widerstand der „Rechten” allmählich durchgeführte taktische Schwen-

1 Die Internationale IX, S. 595 (W. Hirsch); vgl. Thälmann, Reden und Aufsätze, Bd. I, 2.A. Berlin I956, S. 602: „Jeder muß die Tatsache sehen, daß der Imperialismus den Krieg unmöglich entfesseln könnte, wenn die Sozialdemokratie nicht alle imperialist. Kriegsvorbereitungen unterstützte. ... Heute ist sie der aktivste Wegbereiter der imperialist. Kriegsmaßnahmen in der ganzen Welt. Eine besondere Rolle spielt hierbei die Sozialdemokratie in Deutschland."

2 Th. Neubauer, Deutsche Außenpolitik - heute und morgen, Berlin-Wien-Zürich I932, S. II f., I 17. Vgl. z.B.: Reichst.-prot. Bd. 423, S. 444 ff. (Münzenberg); Protokoll der Verhandlungen des XII. Parteitages der KPD, Berlin-Wedding 9.-I6.6.1929, Berlin (1930), S. $300 \mathrm{ff}$. (Remmele).

3 "Mehr Klarheit! Kampf gegen den Reformismus", in: Die Internationale XI (1928), S. $103-108$ ! 
kung wurde in Deutschland vor allem mit dem Auftreten der sozialdemokratischen Minister in der Reichs- und preußischen Regierung und der „reformistischen” Theorie von der Möglichkeit des Aufbaus einer „Wirtschaftsdemokratie” ohne Gewaltanwendung und innerhalb der bestehenden Staatsform illustriert. Diese Tendenzen deuteten die Kommunisten als Symptome einer ideologischen Annäherung zwischen „Faschismus” und „Reformismus”, als Anzeichen der „Faschisierung” der Sozialdemokratie. ${ }^{1}$ In dem vom VI. Weltkongreß beschlossenen Manifest wurde behauptet, „Keime der faschistischen Methoden” fänden sich in der Praxis "vieler sozialdemokratischer Parteien" und der „reformistischen Gewerkschaftsbürokratie". Die notwendig gewordene „Verschärfung des Kampfes gegen die Sozialdemokratie” verschiebe den Schwerpunkt entschieden auf die "Einheitsfront von unten". ${ }^{2}$

In der Anwendung des Schlagworts "Sozialfaschismus" war die KPD in den ersten Monaten der neuen Taktik noch zurückhaltend. Als es jedoch am und nach dem I. Mai 1929 zu blutigen Zusammenstößen zwischen kommunistischen Demonstranten und der von dem Sozialdemokraten Zörgiebel geleiteten Berliner Polizei kam, wurde die Sozialfaschismus-Parole stark in den Vordergrund gerückt. Die SPD wurde zur „führenden Partei des Finanzkapitals” proklamiert, die bewuBt die Kämpfe in Berlin herbeigeführt habe. Es gehe ihr dabei um die Vorbereitung des Bürgerkrieges in Deutschland und des Interventionskrieges gegen die Sowjetunion. „Die Durchführung der Kriegspolitik und Sozialfaschismus, das ist die Plattform, auf die sich die Sozialdemokratie stellt."3 Die psychologische Bedeutung des

1 W. Pieck, „Sozialfaschismus oder Klassenkampf?”, in: Die Rote Fahne XI, Nr. I I X (1 2.5.1928); Dic Internationale XI, S. 438 (A. Fried) usw. - Für den Widerstand und die Ausschaltung der Rechten in der KPD vgl. Tjaden, a.a.O., I, S. 74ff. sowie die Plattform der „Versöhnler” vom Io.6.1929 (Die Internationale XII, S. 431-436); für die KPdSU: R.V. Daniels, The Conscience of the Revolution, Harvard UP 1960, S. 334ff.; Stalin, Werke, Bd. I2, Berlin 1954, S. 6-95.

${ }^{2}$ Vgl. Protokoll. VI. Weltkongreß der KI, Moskau, 17.7.-1.9.1928, Hamburg-Berlin (1929), Bd. I, S. 302 ff. (Thälmann), Bd. IV, S. I 26: „Die Sozialdemokratie geht zu einer aktiv-konterrevolutionären Vorbereitung des Krieges gegen die Sowjetmacht über. Daher ist die Verschärfung des Kampfes gegen die sozialdemokratischen Führer sowohl rechter wie, linker' Färbung und gegen ihre trotzkistischen oder anarchosyndikalistischen Nachläufer notwendig...”, sowie 24 u. 30: „Die Ideologie der Klassenzusammenarbeit, die die offizielle Ideologie der Sozialdemokratie ist, hat viele Berührungspunkte mit der Ideologie des Faschismus. Keime der faschistischen Methoden ... finden sich in der Praxis vieler sozialdemokratischer Parteien, sowie auch in der Praxis der reformistischen Gewerkschaftsbürokratie... Die Verschärfung des Kampfes gegen die Sozialdemokratie verschiebt den Schwerpunkt entschieden auf die Einheitsfront von unten ...".

3 Die Internationale XII, S. 309-330, 38 I-400 (Remmele); Protokoll XII. Parteitag, S. 4 f. (Heckert). - Allerdings war die Bezeichnung "Sozialfaschismus” schon vor dem I.5. immer häufiger gebraucht worden; z.B.: „Der Sozialfaschismus wird immer mehr die offene Ausdrucksform der SPD" (W. Koenen, Inprekorr IX, S. 464). 
„Blutmai” für das Wachsen der Feindschaft zwischen Sozialdemokratie und Kommunisten kann kaum überschätzt werden. Die Veränderung des politischen Klimas zwischen den beiden großen deutschen Arbeiterparteien kam besonders deutlich auf dem im Juni 1929 in Berlin-Wedding stattfindenden letzten KPD-Parteitag vor 1933 zum Ausdruck. Auf ihm wurde zwar auch das Anwachsen der NSDAP bei den sächsischen Landtagswahlen als Symptom der Zunahme des faschistischen Einflusses in Deutschland vermerkt, der Kampf gegen den "Sozialfaschismus” als einer, wie Thälmann meinte, „besonders gefährlichen Form der faschistischen Entwicklung" spielte aber die bei weitem wichtigere Rolle. Nach Thälmanns Definition bestand der Sozialfaschismus darin, "daß er unter dem Deckmantel der sogenannten ,reinen Demokratie' den Weg der faschistischen Diktatur bahnt". ${ }^{1}$ Hermann Remmele, zu der Zeit neben Thälmann und Heinz Neumann der wichtigste KPD-Führer, sagte: „Nun, Genossen, was wir erklären, ist, daß der Sozialfaschismus nichts anderes ist als Sozialismus in Worten, in der Phrase und Faschismus in der Tat. Die Herrschaftsmethoden, die heute Mussolini in Italien anwendet, ... die zu allgemeinen Herrschaftsmethoden in ganz Europa werden und besonders jetzt immer mehr durch die Sozialdemokratie bei ihrem Verschmelzen mit dem Staatsapparat in Deutschland praktiziert werden." All dies diene nicht zuletzt der Vorbereitung eines Krieges gegen die Sowjetunion, auf den Deutschland als „das schwächste Glied in der Kette der imperialistischen Großmächte" sich besonders sorgfältig vorbereiten müsse. ${ }^{2}$ In der theoretischen KPD-Zeitschrift hieß es etwa gleichzeitig sogar, die Sozialdemokratie habe im industriellen Deutschland die Aufgabe, „die faschistische Diktatur vorzubereiten und zu organisieren"; der deutsche Faschismus müsse bei der Struktur des Landes „unvermeidlich" seine Hauptstütze in der SPD haben. Übrigens könne der Terror gegen die Arbeiterklasse in der Demokratie selbst noch brutaler sein als unter einem faschistischen Regime. ${ }^{3}$ - Ganz ohne Widerstreben ist dieser scharfe Kurswechsel anscheinend nicht akzep-

\footnotetext{
1 Protokoll XII. Parteitag, S. 54, 75, vgl. 79 (Thälmann); W. Koenen fühtte die Gewinne der NSDAP auf die "sozialfaschistischen Methoden" der SPD-Führung zurück (Inprekorr IX, S. 1006f.). Vgl. K. Mammach, „Bemerkungen über die Wende der KPD zum Kampf gegen den Faschismus", in: Beitr. z. Gesch. d. dt. Arb.-bew. [BzG] V (1963), S. 658-674, 659. - Aus den Mandatszahlen bei den sächs. Landtagswahlen vom 31.10.1926 u. 1 2.5.1929: KPD $14: 12$, SPD $_{31}$ :33, ASPD $_{4}: 2$, NSDAP $2: 5$.

2 Protokoll XII. Parteitag, S. 205 f., 33 Iff.

${ }^{3}$ R. Gerber (R. Schlesinger), „Das Gesicht des deutschen Faschismus”, in: Die Internationale XII, S. 481-49I, vgl. ebd. XIII, S. 66f.: „In einem Industrieland wie Deutschland ... sind die Träger des Faschismus diese oberste bürgerliche Schicht und ihre korrumpierten arbeiteraristokratischen Agenten in den Massenorganisationen der proletarischen Klasse ..." (Merker).
} 
tiert worden, wenn auch nach dem Ausschluß der „Rechten” und der Ausschaltung der „Versöhnler” aus der Führung Ende 1928 kaum noch oppositionelle Ansichten an die Öffentlichkeit drangen. ${ }^{1}$

Die genaue Feststellung der vom IX. EKKI-Plenum im Februar 1928 beschlossenen Taktik brachte das X. EKKI-Plenum vom Juli 1929. Hatte die Resolution des VI. Weltkongresses noch von „Keimen” faschistischer Methoden der Sozialdemokratie gesprochen, so wurde nunmehr - im Rahmen der Theorie von der ,dritten Periode der kapitalistischen Rekonstruktion" - eine fortgeschrittene "qualitative Veränderung" der Sozialdemokratie zum Sozialfaschismus konstatiert. Es handele sich dabei um einen ,andauernden Prozeß” der Annäherung des Sozialfaschismus an den "reinen” Faschismus. Der Sozialfaschismus werde vielleicht der Faschismus der fortgeschrittenen Industrieländer sein. Manuilski meinte, daß „die Frage des Sozialfaschismus ... heute am schärfsten in der KPD" stehe, während Bela Kun und Martynow die Richtigkeit der Sozialfaschismustheorie mit der Verwandtschaft zwischen der "reformistischen" Parole von der "Wirtschaftsdemokratie" und der faschistischen Korporativideologie sowie der Änderung der sozialen Basis der Sozialdemokratie begründeten und Losowski einen Prozeß der „Faschisierung sämtlicher Scbichten, mit Ausnahme einiger unbedeutender Gruppen" erkennen zu können glaubte. Er meinte sogar, Mussolini habe mit dem Sozialfaschismus angefangen. ${ }^{2}$ Einige Monate vorher hatte Stalin zu einer Zuspitzung des Kampfes auf den linken Flügel der Sozialdemokratie aufgefordert, da „die Überwindung der Sozialdemokratie überhaupt unmöglich ist, ohne die, linken' Sozialdemokraten vernichtend zu schlagen". Diese Parolen wurden die Grundlage eines verstärkten Kampfes gegen die Sozialdemokraten; allerdings mußte zugegeben werden, daß die Umwandlung der sozialdemokratischen in „sozialfaschistische" Parteien ,nur schwer in das Bewußtsein unserer Parteien eingedrungen" sei. ${ }^{3}$

1 ZK-Richtlinien „Der neue Kurs im Jahre 1929” (hektogr.; IISG, Amsterdam).

2 Protokoll. X. Plenum des EKKI, Moskau, 3.7.-19.7.1929, Hamburg-Berlin 1929, S. $39 \mathrm{ff}$. (Kuusinen), $582 \mathrm{ff}$. (Manuilski), 64I ff. (Thälmann), $227 \mathrm{ff}$. (Martynow), I $84 \mathrm{ff}$., I 92 (Kun): „Der Sozialfaschismus bezweckt ... in der Zeit der Erschütterung der Stabilisierung das alte Ziel mit neuen Methoden zu verwirklichen: die Rettung des Kapitalismus. Der Sozialreformismus stirbt in diesem Stadium der Entwicklung ab, er verwandelt sich teilweise zum sozialdemagogischen Element, teilweise zum Element des Massengewaltmittels des Faschismus."; dazu Losowski, ebd., S. 390 ff. Vgl. ebd. S. 359-370 (Ulbricht), und KI XII (1930), S. 379-40I (Martynow). - Im Gegensatz dazu meinte Z. Lippay (Unter dem Banner des Marxismus V, I931, S. $72 \mathrm{ff}$.), die „sich faschisierende Sozialdemokratie” habe im Unterschied zum Faschismus ihre „soziale Basis in der Mehrheit der Arbeiterschaft und nicht unter dem Kleinbürgertum".

3 Stalin, Werke, Bd. 12, S. 19f.; KI XII, S. 379 (Martynow). 
Auf dem von Willi Münzenberg und Henri Barbusse veranstalteten Internationalen Antifaschistenkongreß, der am 9. und Io. März I929 in Berlin abgehalten wurde, war der Nationalsozialismus noch so sehr als quantité négligeable erschienen, daß er völlig vernachlässigt worden war. Stattdessen standen Stahlhelm, Reichsbanner, Sozialdemokratie und die ehemaligen Sozialisten Mussolini und Pilsudski mit ihren „Faschismen” im Mittelpunkt der Angriffe. ${ }^{1}$ Erst nach dem ZK-Plenum vom 24./25. Oktober 1929, als die Anhängerschaft der NSDAP sichtbar anwuchs, wandte sich die KPD auch stärker dem Nationalsozialismus oder "Nationalfaschismus” zu. Oberflächlich gesehen kämpfe dieser auch gegen die Sozialfaschisten, hieß es; aber hierbei handele es sich in Wirklichkeit nur um eine Entlastungsoffensive von rechts für den diskreditierten Sozialfaschismus, der auf diese Weise als das „kleinere Übel” erscheinen solle. Thälmann erklärte schon am I I. Februar 1930 in einer gegen die „sozialfaschistische Regierungsbande", nämlich das von dem Sozialdemokraten Hermann Müller geleitete Kabinett, gerichteten Reichstagsrede, daß ,in Deutschland der Faschismus herrscht". ${ }^{2}$

Nach dem Rücktritt der Regierung Müller am 27. März I 930 wurden gelegentlich von kommunistischer Seite die Begriffe "konservativ" und "faschistisch" gleichgesetzt. Man sprach vom "Brüningfaschismus”, „Nationalfaschismus" und „Sozialfaschismus”. In der KPDFührung wurde Anfang r 930 die gegenüber der SPD einzuschlagende Politik diskutiert. Merker konnte sich mit seiner - weitgehend von Losowski geteilten - Auffassung, daß die sozialdemokratischen Führer und Mitglieder gleichmäßig stark bekämpft werden müßten und die Tätigkeit in den Freien Gewerkschaften aufzugeben sei, nicht durchsetzen. Der sogenannte „Merkerismus” wurde als „linker Doktrinarismus” und „Uberspitzung” abgelehnt. ${ }^{3}$ Grundsätzlich änderte sich dadurch aber nichts an der kommunistischen Politik. Selbst der bei den Reichstagswahlen vom I4. September 1930 sichtbar werdende sprunghafte Anstieg des Nationalsozialismus, der I 8,2\% der Stimmen statt 2,6\% im März I928 erhalten hatte (SPD und KPD 1930: $24,5 \%$ und I 3, I \%), veranlaßte die KPD nicht zu einer Änderung ihrer vor allem gegen die SPD gerichteten Politik. Die strategische Parole der

1 Faschismus, Berlin 1929, und die Resolution des Kongresses: Inprekorr IX, S. $598 \mathrm{f}$.

2 Die Internationale XII, S. 745-750 (J.K.[raus] = Winternitz); Thälmann, Reden, Bd. II, S. 300, 304. Vgl. Protokoll XII. Parteitag, S. 213 f. (A. Kunz), 228 (K. Sindermann); Der Rote Aufbau II (1929), S. I45 ff. (K. Sauerland); KI XI, S. 425-44I (Gerber), 533 ff. (Thälmann), XII, S. 802 ff., I 897-I 926 (Thälmann); Mammach, a.a.O., S. 664, 667.

3 Remmele, "Schritt halten!" in: Die Internationale XIII (1930), S. 135-158, 198-221, 230-259, 259-313, sowie ebd. 65-69 (Merker), 33-36 (J.K. [raus]). - Mammach (S. 668f.) verurteilt die Haltung dex "Sektierer" unter Führung Merkers als „ein sehr verhängnisvolles Unterfangen angesichts der wachsenden faschist. Gefahr". 
„Eroberung der Mehrheit der Arbeiterklasse” mit der Folgerung, den "Hauptstoß" gegen die Sozialdemokratie zu richten, blieb in Kraft; ebenso die Richtlinie, daß die Linkssozialisten als das ,, wirkungsvollste und gefährlichste Kampfmittel des Sozialfaschismus" zu betrachten seien. Sozialdemokratie und Faschismus müßten gemeinsam geschlagen werden; der Sieg über die NSDAP setze die vorherige Niederlage der SPD voraus. Ja es hieß sogar, jeder, der gegen die proletarische Revolution sei, stehe auf der Seite des Faschismus! ${ }^{1}$

Zwar war seit Ende 1930 die Regierung Brüning nur noch als „Regierung der Durchführung der faschistischen Diktatur" bezeichnet worden, diese Abschwächung in der Formulierung war aber zu gering, um agitatorisch genügend bemerkbar und wirksam zu werden. Und auch danach, so etwa im November 193 I nach Breitscheids Darmstädter Einheitsfrontvorschlag, verkündete Thälmann: „Wir sagen den Arbeitern: der Faschismus beginnt nicht, wenn Hitler kommt, er hat längst begonnen." Die ultralinke Politik blieb bis zum Ende (1934/35) „eine mit ihrer Spitze gegen die Sozialdemokratie gerichtete Taktik, dazu bestimmt, sie in den Augen der breiten Arbeitermassen ... zu entlarven". ${ }^{2}$ Jedes Zusammengehen mit der SPD als Organisation wurde abgelehnt, eine konsequente Unterscheidung zwischen "Sozialfaschismus" und Nationalsozialismus als „liberal”, „formalistisch" und „undialektisch" zurückgewiesen. Die KPD hielt sich an die Anweisung, wie sie etwa der EKKI-Sekretär D. Manuilski auf dem XI. EKKI-Plenum im März/April 193 I gab, daß nämlich der Kampf gegen den Faschismus erstens die ,systematische Entlarvung des sozialdemokratischen Betrugs" und zweitens den Kampf gegen die bürgerliche Demokratie bedeute. Die soziale Basis der Sozialdemokratie stimme mehr und mehr mit der des Faschismus überein; beide seien „lediglich zwei Schattierungen" derselben Stütze der bürgerlichen Diktatur. Die SPD wurde als ,aktivster Faktor der Faschisierung” in Deutschland gekennzeichnet. Thälmann meinte allerdings auf dieser Tagung, daß es doch gefährlich sei, „Faschismus und Sozialfaschismus in einen Topf zu werfen”, wenn auch zwischen ihnen kein „prinzipieller klassenmäßiger Gegensatz" bestehe. Auf der Tagung des ZK der KPD im Januar I93 I war die Hauptaufgabe der Partei so formuliert worden: „Liquidierung des Masseneinflusses des Sozialfaschismus”. ${ }^{3}$

1 Vgl. z.B.: Faschismus ohne Maske, Berlin (1930); Was ist Sozialfaschismus?, Berlin (1930), hrsg. v. ZK der KPD.

2 Thälmann, Kampfreden und Aufsätze, Berlin 1932, S. 4I; D. Manuilski, Die Kommunistischen Parteien und die Krise des Kapitalismus, Hamburg I93 I, S. 75 ; vgl. Das Ende der Parteien, Düsseldorf I 960, S. I 55 (E. Matthias).

${ }^{3}$ Inprekorr XI (I93I), S. I 16 I (Manuilski), I 207 (Thälmann); Die Internationale XIV (1931), S. 365 (J. Lenz); vgl. Thälmann, Volksrevolution über Deutschland, (Berlin) 1931, S. 36 . 
Die Periode nach 1930, in der die „Sozialfaschismus"-Parole einer der Hauptbestandteile der kommunistischen Agitation und Propaganda war, soll hier nicht im einzelnen dargestellt werden. ${ }^{1}$ Es möge genügen, daran zu erinnern, daß Thälmann noch auf der wichtigen Tagung des ZK im Februar 1932 vor einer „opportunistischen” Überschätzung des „Hitlerfaschismus” gewarnt und erklärt hat, es gehe darum, die „untrennbare Verbundenheit des Kampfes gegen die Nazis mit unserer Strategie, ... die den Hauptstoß gegen die Sozialdemokratie führt", den Massen verständlich $\mathrm{zu}$ machen. Ausdrücklich abgelehnt wurde bei der Gelegenheit wiederum eine Beschränkung auf die sozialdemokratischen Führer. ${ }^{2}$ Eine gewisse Bereitschaft zur Änderung dieser Taktik war zwar im Frühjahr 1932 im Zusammenhang mit den Führungskämpfen in der KPD-Spitze zu beobachten, sie dauerte jedoch nicht lange an. In dem Aufruf des ZK vom 25. April 1932 „An alle deutschen Arbeiter!" wurden nicht nur ,alle klassenbewußten Betriebsräte und Funktionäre" zum gemeinsamen Kampf gegen den Lohnabbau aufgefordert, sondern es wurde auch die Bereitschaft ausgedrückt, „mit jeder Organisation, in der Arbeiter vereinigt sind, und die wirklich den Kampf gegen Lohn- und Unterstützungsabbau führen will, gemeinsam zu kämpfen". Im Mai und Juni erreichten die Überlegungen in der KPD-Führung über eine Modifizierung der bisherigen Taktik gegenüber der SPD anscheinend ihren Höhepunkt; gleichzeitig wurde die „Antifaschistische Aktion" gegründet. Aber auch in jenen Wochen war die Haltung der KP nicht eindeutig. Während Thälmann in seinem Referat auf der ZK-Tagung vom 24. Mai die Stalinsche Zwillingsbrüder-Theorie als falsch bezeichnete und die unterschiedliche soziale Zusammensetzung von SPD und NSDAP hervorhob sowie am 8. Juni auf einer Funktionärstagung in Berlin sogar die Möglichkeit einer parlamentarischen Einheitsfront von KPD, SPD und Zentrum im preußischen Landtag erwähnte, hieß es in dem am 24. Mai in der „Rote Fahne” veröffentlichen ZK-Aufruf, die KPD werde ,an ihrer Taktik gegenüber der arbeiterfeindlichen Politik der SPD nicht das allergeringste ändern" und keine Kompromisse mit dieser Partei schließen. ${ }^{3}$

1 S. Das Ende der Parteien, S. 66off., und ZfP NF VII (1960), S. $168 \mathrm{ff}$. (Bahne).

${ }^{2}$ Thälmann, Der revolutionäre Ausweg und die KPD, Berlin 1932, S. 24, 49; ders., „Zu unserer Strategie und Taktik im Kampfe gegen den Faschismus”, in: Die Internationale XV (1932), S. 261-292, 274, 284: „Man kann nicbt erfolgreich den Kampf gegen den Hauptfeind, die Bourgeoisie, die Papen-Regierung und ihre nat.-soz. Trabanten führen obne die Strategie des Hauptstoßes gegen die Sozialdemokratie innerhalb der Arbeiterklasse ... Nicht ,Blockpolitik' mit den sozialfaschistischen Führern ... Das schließt in bestimmten Fällen ... die Anwendung der Einheitsfronttaktik von unten und oben im revolutionären Sinne nicht aus."

3 Die Rote Fahne XV, Nr. 80 (14.4.32), 89 (26.4.), I I I (24.5.); Die Antifaschistische 
Als am 20. Juli 1932 Reichskanzler von Papen seinen „nackten faschistischen Staatsstreich" durchführte und die preußische Regierung Otto Braun absetzte, versagte die KPD, wie Wilhelm Pieck 1935 feststellte, weil „ihre alte taktische Orientierung eine falsche war" und sie nicht eingesehen habe, ,daß sie ihre Taktik auf den gemeinsamen Kampf mit der Sozialdemokratie und den Gewerkschaften gegen die faschistische Gefahr hätte umstellen müssen". Zwar forderte damals die KPD agitatorisch ,,vor der proletarischen Öffentlichkeit” auch die sozialdemokratischen Organisationen zum gemeinsamen Generalstreik gegen die Absetzung der bis dahin von ihr so scharf bekämpften Regierung Braun auf, aber unmittelbar danach wurde die Taktik des Hauptstoßes gegen den Sozialfaschismus fortgesetzt. Bei den Wahlen vom 3I. Juli gelang es nach Thälmanns Meinung der KPD, „die Mauer, die dank der Politik der sozialfaschistischen Führer jahrelang zwischen den sozialdemokratischen und freigewerkschaftlich organisierten Arbeitern und dem revolutionären Proletariat bestand, zu durchstoßen" (KPD 5,28 Mill., SPD 7,96 Mill., NSDAP i 3,75 Mill.). Die Folge dieses Wahlausganges war, daß der „Kampf um die eigene Klasse” fortgesetzt und jede "noch so leichte Abschwächung des prinzipiellen Kampfes gegen die SPD", deren Rolle als soziale Hauptstütze der Bourgeoisie sich nach dem 20. Juli noch verstärkt habe, verboten wurde. Das XII. EKKI-Plenum im September und die 3. KPD-Konferenz im Oktober 1932 bestätigten diese Politik. ${ }^{1}$

In dieser erstarrten Situation des Kampfes gegen SPD und NSDAP, wobei der Haupstoß immer noch gegen die „Sozialfaschisten” gerichtet werden sollte, befand sich die KPD Ende Januar I933. Auf Hitlers Ernennung zum Reichskanzler reagierte sie mit der Forderung nach der „Einheit der Arbeiterklasse”; jedoch lehnte sie den von den sozialdemokratischen Führern geforderten „Nichtangriffspakt” für die Zeit des gemeinsamen Kampfes gegen die Nationalsozialisten ab. Der Übergang zur „Einheitsfront von unten und von oben” wurde auch jetzt - abgesehen vom 30. Januar - nicht erlaubt: „Wir Kommunisten lehnen es $\mathrm{ab}$, die Einheitsfront des Handelns von unten in ein Verhandeln der kämpfenden Einheit von oben umzubiegen."”2

Gleichzeitig mit der Festigung des nationalsozialistischen Regimes und der zunehmenden Unterdrückung des Kommunismus und der

Aktion. Dokumentation und Chronik Mai 1932 bis Januar 1933, hrsg. v. H. Karl u. E. Kücklich ..., Berlin 1965, S. 22 ff., 83 ff., vgl. 44 ff. (Thälmann).

${ }^{1}$ Pieck, Der neue Weg zum gemeinsamen Kampf für den Sturz der Hitlerdiktatur, 4.A. Berlin 1954, S. 28 ; Die Internationale XV, S. 312 (Thälmann). Vgl. KI XIV (I932), S. 1073-1343 (Referate EKKI-Plenum); Inprekorr XII, S. 2629-33, 2733-36, $2775-78$ (dto. Thesen).

Die Rote Fahne XVI, Nr. 34 (9.2.1933); vgl. Antifaschist. Aktion, a.a.O., S. 355 . 
anderen politischen Gruppierungen in Deutschland kehrte die KPD wieder zur vollen ultralinken Taktik gegenüber der Sozialdemokratie zurück. Nach der Ablehnung des letzten „Spitzenangebots” an den SPD-Vorstand vom I4. März 1933 warfen die Kommunisten den deutschen Sozialdemokraten vor, offen in das Lager des Faschismus einzuschwenken; die These vom sozialfaschistischen Charakter der SPD sei mit „durchschlagender Gewalt” bestätigt worden. Von nun an wurde bis weit in das Jahr 1934 hinein die Sozialdemokratie wieder als „Hauptfeind” und als „Zwillingsbruder” der Nationalsozialisten bezeichnet; sie war nach offizieller kommunistischer Ansicht auch nach ihrem Verbot die "soziale Hauptstütze der Kapitalsdiktatur". Die kommunistische „Perspektive” sah im Sommer 1933 so aus, daß die Entscheidung der Frage, ob nach dem erwarteten Zusammenbruch des nationalsozialistischen Regimes direkt der Übergang zur Diktatur des Proletariats erfolgen werde oder nicht, vor allem davon abhänge, $o b$ es der KPD gelingen werde, „den Einfluß des Sozialfaschismus im Lager des Proletariats bis zu dessen Heranführung an die entscheidenden Klassenschlachten zu vernichten". Bestätigt wurde diese Fortsetzung der ultralinken Politik vom XIII. EKKI-Plenum im Dezember $1933 .^{1}$

Im Juni und Juli 1934 zeigten sich die ersten Symptome des Abrückens von der „ultralinken” Politik. Offenbar stammen die ersten Überlegungen zu einer grundlegenden Änderung der Taktik aus dem Frühjahr 1934. Wie aus einem Brief Georgi Dimitroffs an die Kommission zur Erörterung seines Referats für den VII. Weltkongreß vom Juni 1934 hervorgeht, lehnte er damals das Festhalten an der Sozialfaschismustheorie ab: „Mit dieser Einstellung verbarrikadieren wir uns oft den Weg zu den sozialdemokratischen Arbeitern." Er bezweifelte die Richtigkeit der These, daß die Sozialdemokratie stets als "soziale Hauptstütze der Bourgeoisie” und ihr linker Flügel als „Hauptgefahr” zu betrachten sei. Stattdessen forderte Dimitroff die Ersetzung der „Einheitsfront nur von unten”, die „ausschließlich als Manöver zur Entlarvung der Sozialdemokratie" angewendet worden sei, „ohne ernsthafte Versuche, die wirkliche Einheit der Arbeiter im Kampf herbeizuführen", durch eine antifaschistische Einheitsfront, die auch eine Zusammenarbeit mit sozialdemokratischen Führern sowie eine

\footnotetext{
1 Rundschau über Politik, Wirtschaft und Arbeiterbewegung II (I933), S. 935 f.; s. Der Faschismus in Deutschland, Moskau-Leningrad 1934, und A. Fogarasi, Der Bankrott der Theorien des Sozialfaschismus am Ende der kapitalistischen Stabilisierung, MoskauLeningrad 1934, S. 88: „Die Rolle, die die Betrugstheorien der Sozialdemokratie in unseren Tagen spielen, liefert wieder einmal die glänzendste Bestätigung für die Feststellung Stalins, daß die Sozialdemokratie einen (objektiv gemäßigten) Flügel des Faschismus und keinen Gegensatz zu ihm darstellt."
} 
Reform der Kommunistischen Internationale - u.a. „mittels einer Einschränkung des schwerfälligen bürokratischen Apparates des EKKI" - einschließen sollte. ${ }^{1}$ Es folgte eine allmähliche völlige Abwendung von der bisherigen „ultralinken” Taktik. Ende 1934 hörte der Gebrauch des Ausdrucks „Sozialfaschismus” auf, und im Laufe der ersten Hälfte des Jahres 1935 bereiteten die Kommunisten mit voller Kraft den Übergang zur Einheits- und Volksfrontpolitik vor, wobei der Widerstand der Mehrheit der KPD-Führung mit Hilfe des EKKI überwunden wurde.

Wie dieser kurze Überblick über die Entwicklungsgeschichte des Begriffs „Sozialfaschismus” und des Verhältnisses der KPD zur Sozialdemokratie und - soweit nötig - zum „Faschismus” in der Weimarer Republik gezeigt hat, war sie nicht nur und nicht einmal in erster Linie die Ânderung der politischen Situation in Deutschland, sondern auch und in zunehmendem Maße die jeweilige „Linie” der Kominternpolitik bestimmend. Diese aber geriet mehr und mehr under den Einfluß der außen- und innenpolitischen Bedürfnisse der Sowjetunion. So falsch es sein würde, bei einer Beurteilung der Politik der KPD etwa die politische Lage in Deutschland selbst außer acht zu lassen, so irreführend wäre es, wollte man die internationale Verflechtung der deutschen Sektion der Komintern nicht gebührend berücksichtigen. ${ }^{2}$

Als der italienische Faschismus eine Macht wurde, vor allem nach dem „Marsch auf Rom” im Oktober 1922, wurde der Begriff „Faschismus" in die kommunistische Terminologie übernommen. Damit verbanden sich für die damalige Situation teilweise beachtenswerte Versuche einer politisch-soziologischen Erklärung dieses neuen Phänomens. Allerdings stellte sich auch sofort die Tendenz ein, mit dem Begriff „Faschismus” alle rechtsradikalen Gruppierungen und Bewegungen zu bezeichnen, darunter in Deutschland den Nationalsozialismus. $\mathrm{Da}$ dieser in den Jahren $1924-1928$ aber nur eine sehr untergeordnete Rolle in der deutschen Politik spielte, wurde die bereits erwähnte Tendenz zur Ausweitung des Begriffs „Faschismus” auf konservative und rechtsradikale Strömungen jeder Art im politischen

1 BzG V (1963), S. 282-284. - Zum Taktieren des langiährigen (1929/34) Leiters der KI, D.Z.Manuilski, in dieser Frage vgl, seine Berichte: Die revolutionäre Krise reift heran. Bericht auf dem I 7. Parteitag über die Tätigkeit der Delegation der KPdSU (B) im EKKI, Moskau-Leningrad I934, S. 35 ff., 65; Die Ergebnisse des VII. Weltkongresses der KI. Bericht ... in der Versammlung des Moskauer und Leningrader Parteiaktivs, September r935, Moskau-Leningrad 1935, S. I $8 \mathrm{ft}$.

2 Vgl. E. Collottis Bemerkungen in: Die KPD 1918-1933, Mailand 196r, S. 17f., 32 f.; allerdings beachtet er m.E. selbst den internationalen Hintergrund der KPD-Politik nicht genügend. 
Tageskampf gefördert. Gegen diese Entwicklung wandte sich mit zum großen Teil berechtigten Argumenten 1928 der damals mit Bucharin verbundene KPI-Führer Palmiro Togliatti. ${ }^{1}$ Die ,gebräuchliche falsche Verallgemeinerung" habe höchstens rein agitatorische Vorteile; es komme aber darauf an, das Phänomen Faschismus aus wissenschaftlichen und politischen Gründen exakt zu analysieren, da von einer richtigen Analyse die kommunistische Haltung ,in einer Periode der Entwicklung und der Vorbereitung einer faschistischen Bewegung" zu bestimmen sei. Ohne eine solche Analyse könne man keine gute Politik machen. Am Beispiel des italienischen Faschismus versuchte Togliatti die charakteristischen Züge einer faschistischen Bewegung herauszuarbeiten. Er sah in ihr, um nur einige seiner Kriterien zu nennen, nicht nur eine kapitalistische Reaktion, sondern gleichzeitig eine Bewegung der kleinbürgerlichen Massen und eine Kampfbewegung von Teilen der kleinen und mittleren Bourgeoisie gegen Teile der alten herrschenden Klassen. Zutreffend warnte Togliatti: „Wenn man von der Theorie ausgeht, daß in der Nacht alle Katzen grau sind, und daß, wenn eine Reaktion eintritt, alles Faschismus ist, dann ist es nicht möglich, gute politische und taktische Positionen zu gewinnen." Genau das aber geschah, in besonders ausgeprägter Form in der Periode der ultralinken Taktik ab 1928. Dabei wurde deutlich, daß der Prozeß der „Funktionalisierung” der marxistisch-leninistischen Theorie weitgehend abgeschlossen war.

Es gehörte zu den wichtigsten Zielen dieser Linkstaktik, die unübersehbar die Nachteile der falschen Internationalisierung zeigte, zu der die Kommunistische Internationale in ihrer Geschichte gelangte, die „entscheidenden Schichten” der Arbeiterschaft für den Kommunismus zu gewinnen, und zwar angeblich, um die ,revolutionäre Situation zu organisieren", ${ }^{2}$ in Wirklichkeit jedoch in erster Linie für die Verhinderung eines Antisowjetkrieges. Bereits Ende 1927 hatte Stalin nachdrücklich hervorgehoben, daß es unmöglich sei, den Kapitalismus zu überwinden, „ohne dem Sozialdemokratismus in der Arbeiterbewegung ein Ende bereitet zu haben". ${ }^{3}$ Als dann im Herbst 1929 beim

1 Ercoli (Togliatti), „Zur Frage des Faschismus”, in: KI IX (1928), S. 1677-1692; vgl. S. Tranquilli (I. Silone), „Borghesia, piccola borghesia e fascismo”, in: lo Stato operaio II (1927), S. I I I-I60. - Anfang I930 schloß sich Togliatti der 'These vom Faschisierungsprozeß der Sozialdemokratie an (s. KI XI, S. 602-622, 1642-57, bes. I654), was Trotzki zu einer höhnischen Bemerkung über die "Servilität” der „Kominternbeamten” veranlaßte (Was nun?, a.a.O., S. 18). - Das Problem des Verhältnisses Togliattis zu Bucharin und Stalin bedarf noch einer näheren Untersuchung.

2 Thälmann, Volksrevolution, a.a.O., S. 23.

3 Werke, Bd. 10, Berlin 1953, S. 216. - Interessant ist ein Vergleich mit der Analyse der Funktion der SPD in der Privatkorrespondenz „Deutsche Führerbriefe” V (1932), Nr. 72-73. 
Herannahen der Krise der Nationalsozialismus in Deutschland stark an Boden gewann, wurde die Politik, den "Hauptstoß” gegen den sozialdemokratischen "Sozialfaschismus" zu führen, nicht abgeschwächt. ${ }^{1}$

Die Einführung dieser Taktik und dieses Schlagworts in Deutschland erleichterten tief verwurzelte antisozialdemokratische Ressentiments, die dem deutschen Kommunismus von seiner Gründungszeit her anhafteten und durch die Politik der SPD immer wieder neue Nahrung erhielten. Die gehäufte Verwendung des abwertenden Begriffs „Faschismus" für alle politischen Gegner, von den Linkssozialisten bis zu den Nationalsozialisten, trug dazu bei, die Bildung einer gemeinsamen Abwehrfront gegen die vom Nationalsozialismus drohende Gefahr unmöglich zu machen. Außerdem hatte diese Politik eine Unterschätzung der Gefahr zur Folge. Und tatsächlich spielte die Erinnerung an die Illegalitätsperiode der KPD im Winter $1923 / 24$, in der die Kommunisten der Polizei ,auf der Nase herumtanzten”, ${ }^{2}$ bei der Situationsbeurteilung der KPD-Führer eine gewisse Rolle.

Die kommunistische Haltung gegenüber der Sozialdemokratie war in der Weimarer Republik stets bestimmt von der Schwierigkeit, daß eine wirkliche Einheitsfronttaktik auf die Dauer die Gefahr mit sich brachte, in der Zusammenarbeit mit dem stärkeren Partner zu sehr das eigene Profil zu verlieren, während eine jeden Kontakt mit der SPD ablehnende Politik der KPD in die Isolierung führte; Aussicht auf Erfolg konnte die Linkstaktik nur beim Herannahen einer revolutionären Situation haben. Die Sozialfaschismus-Theorie, entstanden im Winter 1923/24 unmittelbar nach dem Ende der revolutionären Nachkriegsperiode, war das extremste Kennzeichen für eine der Situation nicht entsprechende radikal linke, „ultralinke” Taktik. Als

\footnotetext{
1 Ich kann Mammach (a.a.O., S. 627 f.) nicht zustimmen, wenn er meint, daß das ZK der KPD seit dem Oktober $x 929$ begonnen habe, „mit der Lösung grundsätzlicher Fragen Schritte einzuleiten, die in die Richtung einer neuen strategischen und taktischen Orientierung führten. ... Das bedeutete praktisch, daß die KPD dazu überging, ihre Hauptkräfte gegen den Faschismus zu richten. Sie verteidigte die Demokratie, ... suchte in verstärktem Maße die Massen zu gewinnen" usw. In der ganzen Periode der ultralinken Politik führte die KPD doch einen Zweifrontenkampf gegen „Faschismus” und „Sozialfaschismus". Es mag sein, daß es ,,in der Parteiführung Überlegungen in dieser Richtung gab"; richtig zu beurteilen wäre dies nur an Hand der Protokolle der ZK- und Polbürositzungen. Die Verfechter einer von der Kominterntaktik abweichenden Politik, zu denen wahrscheinlich zumindest - zeitweise - auch Thälmann gehörte, konnten sich aber jedenfalls bis 1934 nur sporadisch durchsetzen, und nach außen vertraten sie die offizielle Politik.

2 Z.B. Die Internationale XIY, S. 323 (Remmele).

${ }^{3}$ Vgl. Ulbricht, Neues Deutschland XVIII, Nr. I03 (14.4.1963), S. 5: „... Auch die Formulierung vom ,Sozialfaschismus' ist nicht im Karl-Liebknecht-Haus in Berlin erfunden worden." (Auf der 2. ZK-Tagung).
} 
sie $1928 / 29$ auf Geheiß der Kominternzentrale ${ }^{3}$ in erweiterter Form wieder in Gebrauch genommen wurde, konnte zunächst nicht die Rede sein von einem „revolutionären Aufschwung”, wenn auch damals schon davon - nicht von einer revolutionären Situation! - gesprochen wurde. ${ }^{1}$ Als dann die Weltwirtschaftskrise die politische Unruhe stark zunehmen ließ, stellte es sich heraus, daß der Gewinn mehr den rechtsradikalen Nationalsozialisten zufiel; angebracht gewesen wäre also eine gemeinsame Verteidigungspolitik der beiden großen Linksparteien. Stattdessen wurde aus Gründen, die bereits angedeutet wurden, gegen den Widerstand zumindest eines Teils der KPD-Führung die ultralinke Politik, die ihren Höhepunkt beim Volksentscheid der Rechten gegen die preußische Regierung Braun im Herbst 193 I erreichte, verstärkt fortgesetzt.

Die Theorie vom „Sozialfaschismus" der Sozialdemokratie und die aus ihr abgeleiteten politischen Folgerungen waren, wie wiederum Togliatti vor einigen Jahren feststellte, neben dem zu späten Erkennen des wahren Charakters des Nationalsozialismus und der Größe der von ihm drohenden Gefahr (dies waren keine „Privilegien” der KPD) der bedeutendste Irrtum der Kommunistischen Internationale in ihrer Geschichte. ${ }^{2}$ Als sie den Fehler einsah und 1934/35 diesen Irrtum korrigierte, war es für Deutschland zu spät. Mit ihrer ultralinken Politik hatte die Komintern auch gegen die Lehren ihres Hauptgründers Lenin verstoßen, der sich bereits 1920 gegen den linken Radikalismus als eine „Kinderkrankheit des Kommunismus” gewandt hatte. Er schrieb damals: „Das sicherste Mittel, um eine ... Idee zu diskreditieren und $z u$ schädigen, besteht darin, daß man bei der Verteidigung dieser Idee bis zur Absurdität geht. Denn jede Wahrheit kann, ... wenn man sie übertreibt, wenn man die Grenzen ihrer wirklichen Geltung überschreitet, zur Absurdität werden..."3 Die Erkenntnis, daß die Sozialfaschismustheorie solch eine historisch folgenschwere Absurdität war, gewinnt allmählich auch bei den deutschen Kommunisten an Boden. ${ }^{4}$

\footnotetext{
1 Vgl. Ewert am 4.7.1928 im Reichstag: „... die objektiven Bedingungen für die Machteroberung des Proletariats sind in Deutschland gegeben. Es gilt, die subjektiven Bedingungen zu schaffen im Kampfe gegen die reformistische Politik, die eins der entscheidendsten Hemmnisse für die Durchführung der sozialen Revolution in Deutschland ist." (Reichst.-prot. Bd. 423, S. 72).

2 Rinascita XVI (1959), S. $477 \mathrm{f}$.

${ }^{3}$ Lenin, Sämtliche Werke, Bd. XXV, Wien-Berlin 1930, S. 248.

4 Vgl. Ulbrichts Bemerkung in: Ulbricht, Zur Geschichte der deutschen Arbeiterbewegung, Bd. I, Berlin 1953, S. 455; ders. in: Protokoll der Verhandlungen des VI. Parteitages der SED, 15.-21.1.1963, Bd. I, Berlin I963, S. 237; Neues Deutschland, a.a.O.; Das Ende der Parteien, a.a.O., S. 719 f.; H. Matern, Im Kampf für Frieden, Demokratie und Sozialismus, Bd. I, Berlin I963, S. 572 (IML); BzG V (1963), S. 232 ff., 237 : „Verursacht durch die antikommunistische Politik der rechten Führer der SPD, fand eine solche
} 
politisch falsche und schädliche These Stalins Eingang, daß Faschismus und Sozialdemokratie ,Zwillingsbrüder' seien, was zu dem Begriff ,Sozialfaschismus' führte und einer schematischen Gleichsetzung des Kampfes gegen den Opportunismus in der Arbeiterbewegung mit dem Kampf gegen die reaktionärsten Elemente der Bourgeoisie Vorschub leistete. Dazu kam die falsche Zuspitzung des Kampfes gegen den Opportunismus in erster Linie auf die linken Sozialdemokraten." (S. Ittershagen - H. Karl - W. Wimmer); Antifaschist. Aktion, a.a.O., S. $1_{4} *$ f.

- Erst nach der Drucklegung habe ich Kenntnis nehmen können von G. Cafornos Einleitung zu „Il dibattito al X Plenum della Terza Internazionale sulla socialdemocrazia, il fascismo e il socialfascismo" (in: Critica marxista III, I965, Nr. 4 , S. I $17-142$, bes. I 30 , 137), in der hervorgehoben wird, daß die ursprünglich von einer Gruppe von Intellektuellen geführte KPD 1929, nach dem Ausschluß der ,rechten" und „linken” Abweichungen, ,a essere un partito povero di intellettuali, povero dunque di contributi che garantissero la continuità con le grandi tradizioni culturali e ideologiche a cui per la sua origine il partito si riallacciava". Diese Folge der in der KPD besonders systematisch durchgeführten „Bolschewisierung” hat sicherlich zu der schnellen Übernahme auch der „Sozialfaschismus"-Theorie beigetragen. Lenin hatte schon früh gewarnt: „Werdet Ihr alle nicht besonders gefügigen, aber klugen Leute wegjagen, und Euch nur die gehorsamen Dummköpfe lassen, so werdet Ihr die Partei bestimmt zugrunde richten." (zit. Bucharin, Prot. VI. KI-Kongreß, a.a.O., Bd. I, S. 553). Daß die SPD ihrerseits eine unfreundliche und oft feindliche Haltung gegenüber der KPD eingenommen hat und daß dadurch die Einführung der ,ultralinken" Taktik erleichtert wurde, ist ebensowenig zu bezweifeln wie die Tatsache, daß die Zunahme der Feindschaft zwischen beiden Parteien seit 1928/29, für die die "Sozialfaschismus"-These symbolisch ist, in erster Linie von der taktischen Schwenkung der KI ihren Ausgang nahm. Caforno kritisiert, Togliatti folgend, die damalige KI-Taktik als absolut schematisch; die Stalinsche Analyse habe, meint er, zwar die Grundelemente des damals in Westeuropa vor sich gehenden Prozesses erkannt, jedoch wegen ihres Schematismus daraus völlig falsche Schlußfolgerungen gezogen (a.a.O., S. I35 f.; vgl. G. Amendola, ebd., S. 24 ff.). 